\title{
Still Something to Discover: Novel Insights into Escherichia coli Phage Diversity and Taxonomy
}

\author{
Imke H. E. Korf ${ }^{1}$, Jan P. Meier-Kolthoff ${ }^{1}$, Evelien M. Adriaenssens ${ }^{2}{ }^{\circledR}$, Andrew M. Kropinski ${ }^{3}{ }^{(0)}$, \\ Manfred Nimtz ${ }^{4}$, Manfred Rohde ${ }^{5}$, Mark J. van Raaij ${ }^{6}$ and Johannes Wittmann ${ }^{1, *}$ \\ 1 Leibniz Institute DSMZ-German Collection of Microorganisms and Cell Cultures, 38124 Braunschweig, \\ Germany; ims16@dsmz.de (I.H.E.K.); jan.meier-kolthoff@dsmz.de (J.P.M.-K.) \\ 2 Quadram Institute Bioscience, Norwich Research Park, Colney Lane, Norwich NR4 7UQ, UK; \\ evelien.adriaenssens@quadram.ac.uk \\ 3 Departments of Food Science and Pathobiology, University of Guelph, Guelph, ON N1G 2W1, Canada; \\ Phage.Canada@gmail.com \\ 4 Protein Analytics Platform, Helmholtz-Centre for Infection Research (HZI), 38124 Braunschweig, Germany; \\ Manfred.Nimtz@helmholtz-hzi.de \\ 5 Central Facility for Microscopy, Helmholtz-Centre for Infection Research (HZI), 38124 Braunschweig, \\ Germany; Manfred.Rohde@helmholtz-hzi.de \\ 6 Department of Macromolecular Structure, Centro Nacional de Biotecnologia CNB-CSIC, 28049 Madrid, \\ Spain; mjvanraaij@cnb.csic.es \\ * Correspondence: johannes.wittmann@dsmz.de
}

Received: 14 March 2019; Accepted: 15 May 2019; Published: 17 May 2019

\begin{abstract}
The aim of this study was to gain further insight into the diversity of Escherichia coli phages followed by enhanced work on taxonomic issues in that field. Therefore, we present the genomic characterization and taxonomic classification of 50 bacteriophages against $E$. coli isolated from various sources, such as manure or sewage. All phages were examined for their host range on a set of different $E$. coli strains, originating, e.g., from human diagnostic laboratories or poultry farms. Transmission electron microscopy revealed a diversity of morphotypes (70\% Myo-, $22 \%$ Sipho-, and $8 \%$ Podoviruses), and genome sequencing resulted in genomes sizes from $\sim 44$ to $\sim 370 \mathrm{~kb}$. Annotation and comparison with databases showed similarities in particular to T4- and T5-like phages, but also to less-known groups. Though various phages against $E$. coli are already described in literature and databases, we still isolated phages that showed no or only few similarities to other phages, namely phages Goslar, PTXU04, and KWBSE43-6. Genome-based phylogeny and classification of the newly isolated phages using VICTOR resulted in the proposal of new genera and led to an enhanced taxonomic classification of E. coli phages.
\end{abstract}

Keywords: bacteriophage; Escherichia coli; taxonomy; diversity; genomics

\section{Introduction}

Though being a ubiquitous and most of the time harmless commensal, Escherichia coli (E. coli) is among the most common pathogens known to both human and veterinary medicine. Moreover, Shigella spp., the causative agent of human shigellosis, is directly imbedded within E. coli diversity [1]. Many strains cause various diseases in humans and animals due to different mechanisms of pathogenicity. According to the site of infection, those diseases can be grouped as intestinal, e.g., causing diarrhea, or extraintestinal, e.g., causing urinary tract infections (UTI) or septicaemia [2]. The intestinal group can be further differentiated into six different pathotypes [3,4], namely enteropathogenic $E$. coli (EPEC), enterohaemorrhagic E. coli (EHEC), enterotoxigenic E. coli (ETEC), enteroinvasive E. coli (EIEC), enteroaggregative E. coli (EAEC), and diffusely adherent $E$. coli (DAEC) dependent on phylogeny or 
presence of virulence factors. In case of the extraintestinal E. coli, they are classified based on the diseases that are associated with them, e.g., uropathogenic E. coli (UPEC) or neonatal meningitis-associated E. coli (NMEC) [5]. A genome-based analysis of a comprehensive E. coli dataset proposed a subdivision of E. coli into five subspecies and 14 phylogroups [1].

In poultry, E. coli is a major causative agent of colibacillosis, which creates significant economic losses and is commonly treated by antibiotics, which in turn promotes the selection of multidrug-resistant (MDR) bacteria. Since antibiotic resistance is also a major concern in E. coli, extended-spectrum beta-lactamase ESBL-producing Enterobacteriaceae are also on the World Health Organization (WHO) priority list for pathogens against which solutions must urgently be developed. Thus, bacteriophages have resurfaced as one putative alternative to antibiotics [6] and some reports of phage therapy to treat $E$. coli infections have already been reported for veterinary and human medicine $[7,8]$.

Bacteriophages are assumed to be the most abundant biological entities on earth with an estimated number of $4.8 \times 10^{31}$ phage particles in the whole biosphere [9]. This abundance makes them global players in different ecological processes, such as biogeochemical cycling [10-12]. Besides their impact on ecology and evolution, they also played an important role in the development of modern molecular biology. Many pioneering experiments based on bacteriophages and their interaction with their hosts were performed that resulted in the discovery of basic aspects of today's molecular biology, such as the proof of DNA as the hereditary material (Hershey and Chase, 1952), restriction and modification of DNA (Arber, 1960s), or phage Lambda as a model for gene regulation [13]. Those well-studied workhorses, such as $\lambda$, members of the T-series, P1, or N4-like phages, are still strongly used in research for different questions.

However, although the number of sequenced phage genomes is constantly rising [14], only a relatively small number is well-characterized and taxonomically classified $[15,16]$. The International Committee on Taxonomy of Viruses (ICTV) currently classifies caudoviral Escherichia phages into 37 genera and 157 species. N.B. ICTV does not classify viral strains, i.e., those phages which show $\geq 95 \%$ DNA sequence identity $[17,18]$. Furthermore, though a lot of new relatives of previously classified phages have been isolated over the years, there are still genomic orphans in the databases. In regard to Escherichia phages, several studies have recently been performed looking at the diversity of those phages in different habitats, such as water or even food $[19,20]$. This study provides further insight into the diversity of E. coli phages via morphology and genome-based phylogeny and classification. Therefore, samples from different sources, such as surface water, manure, sewage, or animal feces, were used to isolate phages on a diverse set of $E$. coli strains with different serotypes from mostly human or animal origin.

\section{Materials and Methods}

\subsection{Bacterial Strains and Growth Conditions}

E. coli isolates DSM 101101-101142 come from clinical material around Hameln (Germany), DSM 103242-103251 originate from poultry carcass skin from France, Belgium, Netherlands, and Germany, and APEC (avian pathogenic E. coli) strains (DSM 103254-103266) were isolated in Germany. Together with the laboratory strain DSM 498, they were used for phage isolation, propagation, and host range analysis. Serotypes of the isolates were determined according to the Ørskov typing scheme [21] and the information can be found in Table S1. To ensure the diversity of the strains used for host range analysis, a selected number of strains was characterized by Alere Technologies GmbH E. coli PanType [21,22]. The E. coli isolates were grown in lysogeny broth (LB) (2.5\% Miller's LB Broth Base ${ }^{\mathrm{TM}}$ powder (Invitrogen, Carlsbad, CA, USA) or on agar plates of LB medium supplemented with $1.5 \%$ bacteriological agar No. $1(w / v)$ (Oxoid ${ }^{\mathrm{TM}}$, Thermo Fisher Scientific, Waltham, MA, USA)) overnight at $37^{\circ} \mathrm{C}$ unless stated otherwise. To test the specificity of the phages KWBSE43-6 and Goslar, we used different Klebsiella strains from the collection of the German Collection of Microorganisms and Cell Cultures (DSMZ) for an extended host range analysis. The growth conditions are summarized in Table S2. 


\subsection{Phage Isolation, Purification, and Propagation}

Phages were isolated from different samples using 29 different $E$. coli strains between November 2015 and August 2016 (Table S3).

After centrifugation, samples were filtrated (membrane syringe filter $0.45 \mu \mathrm{m}$, Sartorius (Germany)) and mixed with equal amounts of double-concentrated LB broth and 1/20 volume logarithmic growing host strain. After incubation at $37^{\circ} \mathrm{C}$ overnight, cells were sedimented by centrifugation and the supernatant was filtrated. To isolate phages, appropriate dilutions of the enrichment were mixed with soft-agar (2.5\% Miller's LB Broth Base ${ }^{\mathrm{TM}}$ powder (Invitrogen, Thermo Fisher Scientific, USA) and $0.3-0.7 \%$ bacteriological agar No. 1 ( $w / v)$ (Oxoid ${ }^{\mathrm{TM}}$, Thermo Fisher Scientific, USA)) containing the corresponding host and overlaid on an agar plate. After incubation at $37^{\circ} \mathrm{C}$ for $12-18 \mathrm{~h}$, single plaques were suspended in SM buffer (100 mM NaCl, $8 \mathrm{mM} \mathrm{MgSO}_{4}, 50 \mathrm{mM}$ Tris-HCl, pH 7.5 (Merck, Germany)) using a pipette tip followed by striking on a double agar plate. At least four consecutive single plaque isolates were processed for a pure phage preparation, which was used for further propagation. In general, logarithmic growing cultures were infected with phages at multiplicicty of infection MOI 0.1 , and incubated for $10 \mathrm{~min}$ at room temperature and then at $37^{\circ} \mathrm{C}$ and $123 \mathrm{rpm}$ until the lysis was completed or for $5 \mathrm{~h}$. After centrifugation and filtration, the titer of the lysate was determined using the double agar method and the lysate was stored at $10{ }^{\circ} \mathrm{C}$.

\subsection{Purification via CsCl Gradient and Morphological Analysis via Transmission Electron Microscopy}

For preparation of the $\mathrm{CsCl}$ gradient, $300 \mathrm{~mL}$ high titer lysates of our phages ( $>10^{9}$ plaque forming units $(\mathrm{PFU}) / \mathrm{mL}$ ) were centrifuged for $2 \mathrm{~h}$ at 16,000 rpm (Sorvall RC6Plus, F21S $8 \times 50 \mathrm{Y}$ ) in order to concentrate the phages. Phages were resuspended in $2 \mathrm{~mL} \mathrm{SM}$ buffer buffer $(100 \mathrm{mM} \mathrm{NaCl}, 8 \mathrm{mM}$ $\mathrm{MgSO}_{4}$, and $50 \mathrm{mM}$ Tris-HCL ( $\mathrm{pH}$ 7.5)). After incubation at room temperature for $2 \mathrm{~h}$, the phages were purified by ultracentrifugation in a discontinuous $\mathrm{CsCl}$ gradient $(0.5 \mathrm{~mL} \mathrm{CsCl}$ solution with densities of 1.6, 1.5, 1.4, and 1.3) for $2 \mathrm{~h}$ at $15^{\circ} \mathrm{C}$ and 35,000 rpm in an SW 60 Ti rotor. Phage bands were then removed and dialyzed against $\mathrm{SM}$ buffer again [23].

For TEM analysis, phages were prepared for analysis as previously described [24]. Briefly, phages were allowed to adsorb onto thin carbon support films. Afterwards, they were negatively stained with $2 \%(w / v)$ aqueous uranyl acetate, $\mathrm{pH}$ 5.0. Samples were examined in a Zeiss EM 910 or Zeiss Libra120 Plus transmission electron microscope (Carl Zeiss, Oberkochen, Germany) at an acceleration voltage of $80 \mathrm{kV} / 120 \mathrm{kV}$ at calibrated magnifications using a crossed line grating replica. Size determination of heads and tails was performed using ITEM Software (Olympus Soft Imaging Solutions, Münster) from at least 3-10 different phage particles and further classification was done according to Ackermann [25]. Based on their morphotypes, phages were then named according to Adriaennsens and Brister [17], e.g., Escherichia phage R5505, which revealed characteristics of a myovirus that was named vB_EcoM_R5505. For convenience, only the short names of the phages are used in the text.

\subsection{Host Spectrum}

The phage host range was determined by spotting serial dilutions on double agar plates containing $100 \mu \mathrm{L}$ of a logarithmic culture of the potential host. After incubation for $14-16 \mathrm{~h}$ at $37^{\circ} \mathrm{C}$, the plates were examined for lysis. The host was classified as sensitive when single plaques could be detected.

\subsection{DNA Isolation and Sequencing}

DNA from phage lysates was extracted by phenol-chloroform and precipitated by $3 \mathrm{M}$ sodium acetate and $100 \%$ ethanol as previously described [21] or following the manufacturer's instructions of the Phage DNA Isolation Kit (Norgen Biotek). Briefly, $300 \mathrm{~mL}$ high titer lysate $\left(10^{10} \mathrm{PFU} / \mathrm{mL}\right)$ was precipitated with 10\% polyethylene glycol 8000 (Merck, Germany) and $1 \mathrm{M}$ sodium chloride (Merck) followed by centrifugation for $30 \mathrm{~min}$ at 10,000 rpm (Sorvall RC 6 Plus with rotor F21S $8 \times 50 \mathrm{y}$, Thermo Scientific ${ }^{\mathrm{TM}}$, USA). The pellet was resuspended in 2-4 mL SM-buffer and treated with 10-fold 
reaction buffer (100 mM Tris- $\mathrm{HCl}(\mathrm{pH} 7.5), 25 \mathrm{mM} \mathrm{MgCl}_{2}$, und $1 \mathrm{mM} \mathrm{CaCl}_{2}$, Thermo Fisher Scientific, USA), $0.2 \mathrm{mg} / \mathrm{mL}$ RNase A (Thermo Fisher Scientific, USA), and $0.002 \mathrm{U} / \mu \mathrm{L}$ DNase I (Thermo Fisher Scientific, USA) followed by incubation overnight at $37^{\circ} \mathrm{C}$ and $300 \mathrm{rpm}$ in a Thermomix (Eppendorf, Germany). DNA was isolated using phenol-chloroform extraction and precipitated by $3 \mathrm{M}$ sodium acetate and $100 \%$ ethanol. After incubation for $15 \mathrm{~min}$ at $-80{ }^{\circ} \mathrm{C}$, DNA was pelleted by centrifugation and washed twice with 70\% ethanol. The pellet was air-dried and solved in 50-200 $\mu \mathrm{L}$ TE-buffer $(10 \mathrm{mM}$ Tris-HCl, 1 mM EDTA, pH 8, Merck, Germany). The concentration was determined using the Qubit ${ }^{\circledR}$ dsDNA HS Assay Kit (Thermo Fisher Scientific, USA) following the manufacturer's instructions.

\subsection{Library Preparation and Whole Genome Sequencing}

Phage genomes were sequenced using PacBio RSII and Illumina MiSeq technologies. A SMRTbell ${ }^{\mathrm{TM}}$ template library was prepared according to the instructions from Pacific Biosciences following the Procedure \& Checklist Greater than $10 \mathrm{~kb}$ Template Preparation and Sequencing. Briefly, for preparation of $10 \mathrm{~kb}$ libraries, $\sim 4 \mu \mathrm{g}$ of each phage DNA was sheared using a Covaris S220 focused-ultrasonicator (Woburn, MA, USA) according to the manufacturer's instructions. DNA was end-repaired and ligated overnight to barcoded SMRTbell ${ }^{\mathrm{TM}}$ adapters applying components from the DNA/Polymerase Binding Kit P6 from Pacific Biosciences. Reactions were carried out according to the manufacturer's instructions. Seven to eight SMRTbell ${ }^{\mathrm{TM}}$ templates were combined in equimolar part. Each sample was either Exonuclease treated for removal of incompletely formed reaction products or pulsed-field gel electrophoresis was carried out using a BluePippin ${ }^{\mathrm{TM}}$ to select for fragments greater than $4 \mathrm{~kb}$. The latter was performed according to the manufacturer's instructions (Sage Science). Conditions for annealing of sequencing primers and binding of polymerase to a purified SMRTbell ${ }^{\mathrm{TM}}$ template were assessed with the Calculator in RS Remote, Pacific Biosciences. Single molecule real time (SMRT) sequencing was carried out on the PacBio RSII (Pacific Biosciences) taking one 240-min movie for each SMRT cell. In total, one SMRT cell was run for each assay. Alternatively, libraries were prepared as described by Baym et al. [26]. An amount of $0.5 \mathrm{ng}$ DNA was enzymatically fragmented using the Nextera DNA Library Preparation Kit (Illumina, FC-121-1030) for 10 min at $55^{\circ} \mathrm{C}$. After addition of $11 \mu \mathrm{L}$ KAPA-master mix (Library Amplification Kit, Kapa Biosystems) and $4.4 \mu \mathrm{L}$ of each index primer, the reaction mixture was incubated according the following program: $3 \mathrm{~min}$ at $72{ }^{\circ} \mathrm{C}, 5 \mathrm{~min}$ at $98^{\circ} \mathrm{C}$, $13 \times\left(10 \mathrm{~s}\right.$ at $98{ }^{\circ} \mathrm{C}, 30 \mathrm{~s}$ at $62{ }^{\circ} \mathrm{C}, 30 \mathrm{~s}$ at $\left.72{ }^{\circ} \mathrm{C}\right), 5 \mathrm{~min}$ at $72{ }^{\circ} \mathrm{C}$. For PCR clean-up and size selection, the PCR product was incubated with magnetic beads (Ampure XP, Beckman Coulter). The pool of DNA libraries was adjusted to $4 \mathrm{nM}$ and sequenced using MiSeq technology (Reagent Kit v3, 600-cycle, MS-102-3003, Illumina).

\subsection{SDS-PAGE Analysis of Phage Proteins}

Phages from CsCl-gradient-purified lysates were heated for $7 \mathrm{~min}$ at $95^{\circ} \mathrm{C}$ with loading buffer (0.1 M DTT, $0.01 \%$ bromophenol blue sodium salt, $1.3 \%$ SDS, $22 \%$ glycerol, $0.13 \mathrm{M}$ TRIS) at the ratio 4:1. Proteins were separated by electrophoresis on 15\% SDS-PAGE gels (running gel: 15\% acrylamide- $, N, N^{\prime}$-methylenebisacrylamide-solution ratio 37.5:1 (Carl Roth, Germany), $0.1 \%$ SDS, $0.1 \%$ APS in $0.375 \mathrm{M}$ TRIS-HCl, pH 8.8; stacking gel: $10 \%$ acrylamide- $, N, N^{\prime}$-methylenebisacrylamide-solution ratio $37.5: 1,0.1 \%$ SDS, $0.1 \%$ APS in $0.05 \mathrm{M}$ TRIS-HCl, $\mathrm{pH}$ 6.8) in SDS-PAGE buffer (0.2 M glycine, $0.025 \mathrm{M}$ TRIS, $1 \%$ SDS, pH 8.3). Gels were incubated in fixation solution (50\% methanol and $10 \%$ acetic acid) for $30 \mathrm{~min}$, protein bands visualized by staining with $0.25 \%$ Coomassie R250 in fixation solution for $1 \mathrm{~h}$, and background color was removed with decolorizer solution (5\% methanol, $7.5 \%$ acetic acid) overnight. Prominent protein bands were cut in slices, which were washed in distillated water overnight and afterwards dried in air.

\subsection{Time-Limited Digestion with BAL 31}

For further analysis and to obtain a hint at a putative circular permutation of the genome, phage DNA was treated with exonuclease BAL 31 and restriction enzymes as previously described [27]. 


\subsection{MALDI-TOF Analysis}

Peptide fingerprinting analysis by MALDI-TOF analysis was performed as described previously [28]. Briefly, excision of stained protein bands was followed by two washing steps with water for $5 \mathrm{~min}$. After that, gel slices were dehydrated with $200 \mu \mathrm{L}$ of $50 \%$ acetonitrile for $5 \mathrm{~min}$, then reduced using $20 \mathrm{mM}$ DTT in $200 \mu \mathrm{L}$ of $0.1 \mathrm{M} \mathrm{NH}_{4} \mathrm{HCO}_{3}$ for $30 \mathrm{~min}$ at $56{ }^{\circ} \mathrm{C}$ and dehydrated again followed by rehydration with $55 \mathrm{mM}$ iodoacetamide in $0.1 \mathrm{M} \mathrm{NH}_{4} \mathrm{HCO}_{3}$ and incubated for $30 \mathrm{~min}$ at room temperature (RT) in the dark. Dehydrated gel pieces were completely dried in a SpeedVac concentrator for $10 \mathrm{~min}$. They were reswelled in $50 \mu \mathrm{L}$ of digestion solution containing trypsin, followed by incubation overnight at $37^{\circ} \mathrm{C}$. Peptides were extracted by adding $50 \mu \mathrm{L}$ of acetonitrile, followed by incubation with vigorous shaking for $15 \mathrm{~min}$ at $37^{\circ} \mathrm{C}$. After discarding the supernatants, gel slices were treated with $50 \mu \mathrm{L}$ of $5 \%$ formic acid with vigorous shaking for $15 \mathrm{~min}$ at $37^{\circ} \mathrm{C}$. Afterwards, $50 \mu \mathrm{L}$ of acetonitrile was added, followed again by incubation with vigorous shaking for $15 \mathrm{~min}$ at $37^{\circ} \mathrm{C}$. Supernatants were combined with the removed supernatants and concentrated using a SpeedVac concentrator. Forty microliters $(40 \mu \mathrm{L})$ of $32 \%$ methanol $/ 0.25 \% \mathrm{HCOOH}$ was added, followed by ultrasound treatment for $3 \mathrm{~min}$ and analysis by MALDI Ultraflex-TOF/TOF. Results were compared with a database of predicted phage proteins using Mascot (an in-house system).

\subsection{Genome Sequencing, Assembly, and Annotation}

For PacBio RS II sequencing, phage genome sequence assembly was performed using the "RS_HGAP_Assembly.3" protocol included in SMRTPortal version 2.2.0., applying standard parameters as previously described [24]. Sequences generated with Illumina technology were assembled using SPAdes (3.12.0) with the careful option (55kmer) [29]. For all phages, a single contig was obtained that was linearized due to recognition of distinct start and end points in the phage assemblies where the majority of sequences ended abruptly. If ends could not be detected, such as for T4-like phages with circularly permuted genomes, assembled sequences were arranged according to the genomic organization of closely related and already published phages. A quality check of the final phage genomes regarding overall coverage was done using SMRT View and IGV [30]. All phage genomes were annotated with Prokka 1.8 using different databases (Markov model profile databases, including Pfam and TIGRFAMs). A search was performed using hmmscan from the HMMER 3.1 package [31]). Additionally, the pVOG database was included our analysis [32]. Genomes were then manually curated with Artemis [33]. Intergenic genome regions were analyzed for putative transcriptional regulation elements with ARNOLD [34]. A search for tRNA genes was done with the tRNAscan-SE program v1.2.1 [35]. Homology assignments were based on amino acid sequence alignment searches (BLASTP against non-redundant protein sequences and the UniProtKB/Swiss-Prot database) and were accepted only if the statistical significance of the sequence similarities (E value) was less than $1 \times 10^{-5}$, the percentage query cover was $\geq 60 \%$, and the percentage identity between the aligned sequences was $\geq 35 \%$.

\subsection{VICTOR Analysis}

The complete dataset of newly isolated phages, including reference phage species, was subjected to a state-of-the-art genome-based analysis using VICTOR [36], the Virus Classification and Tree Building Online Resource (freely available at https://victor.dsmz.de). VICTOR was shown to yield either nucleotide- or amino-acid-based phylogenies having a high agreement with the ICTV classification and the majority of taxa was well-supported as monophyletic. Recent applications, for example, include the successful classification of newly isolated roseophages into a novel genus and subfamily [37]. VICTOR makes extensive use of the Genome-BLAST Distance Phylogeny (GBDP) method [38] under settings recommended for prokaryotic viruses [36]. The phylogenetic trees (with branch support) and taxon boundaries at the species, genus, subfamily, and family level, as reported and recommended by VICTOR, were finally visualized with iTOL [39] after preparing the annotation with the R program table2itol (https://github.com/mgoeker/table2itol). For analysis with VICTOR, BLASTn analysis of our phage genomes against the database of tailed phages (taxid:28883) was performed first to identify 
related phages with a high identity score (October 2018). When phages belonged to a yet unclassified group, we tried to include all of them in further analyses. For already classified genera with a high number of members, such as Tequatrovirus or Tequintavirus, we chose the type phages and best hits to maintain dataset sizes still suitable for visualization. Before the VICTOR analyses, reference phages HX01 and PDX were reannotated using Prokka to provide comparable numbers of coding sequences (CDS) since the submitted GenBank file (MG963916, JX536493) apparently missed several CDS.

\section{Results and Discussion}

\subsection{Morphological Analysis via TEM}

All newly isolated phages of this study were morphologically analyzed via transmission electron microscopy. This analysis revealed that all belong to the order Caudovirales with representatives of three different morphotypes. The majority belonged to the myoviruses $(70 \%)$ and siphoviruses $(22 \%)$. Only four isolates $(8 \%)$ showed a characteristic morphology of a podovirus, indicating that a substantial diversity of phages was isolated during this study. Among the isolated myoviruses, different tail lengths, varying between $\sim 100 \mathrm{~nm}$ and $\sim 220 \mathrm{~nm}$, and various tail fibers, their head widths ranging from 70 to $\sim 130 \mathrm{~nm}$ (Figure 1, Table 1), were detected. Analysis of the isolated siphoviruses revealed isometric head widths ranging from $\sim 60$ to $\sim 80 \mathrm{~nm}$ and tail lengths ranging from 140 to $\sim 220 \mathrm{~nm}$. Some phages, such as, for instance, phage HDK1, revealed slightly prolate heads. Most of the examined siphoviruses displayed relatively flexible tails and also tail fibers at the end (Figure 2). Finally, phages KAW1A4500, R4596, and PTXU04 revealed typical characteristics of a podovirus with icosahedral heads and short tails, while the fourth member, WFI101126, showed a more uncommon C3-like morphology with an elongated head (length:width ratio >3) of about $144 \mathrm{~nm}$ (Figure 3) as already reported elsewhere $[40,41]$.
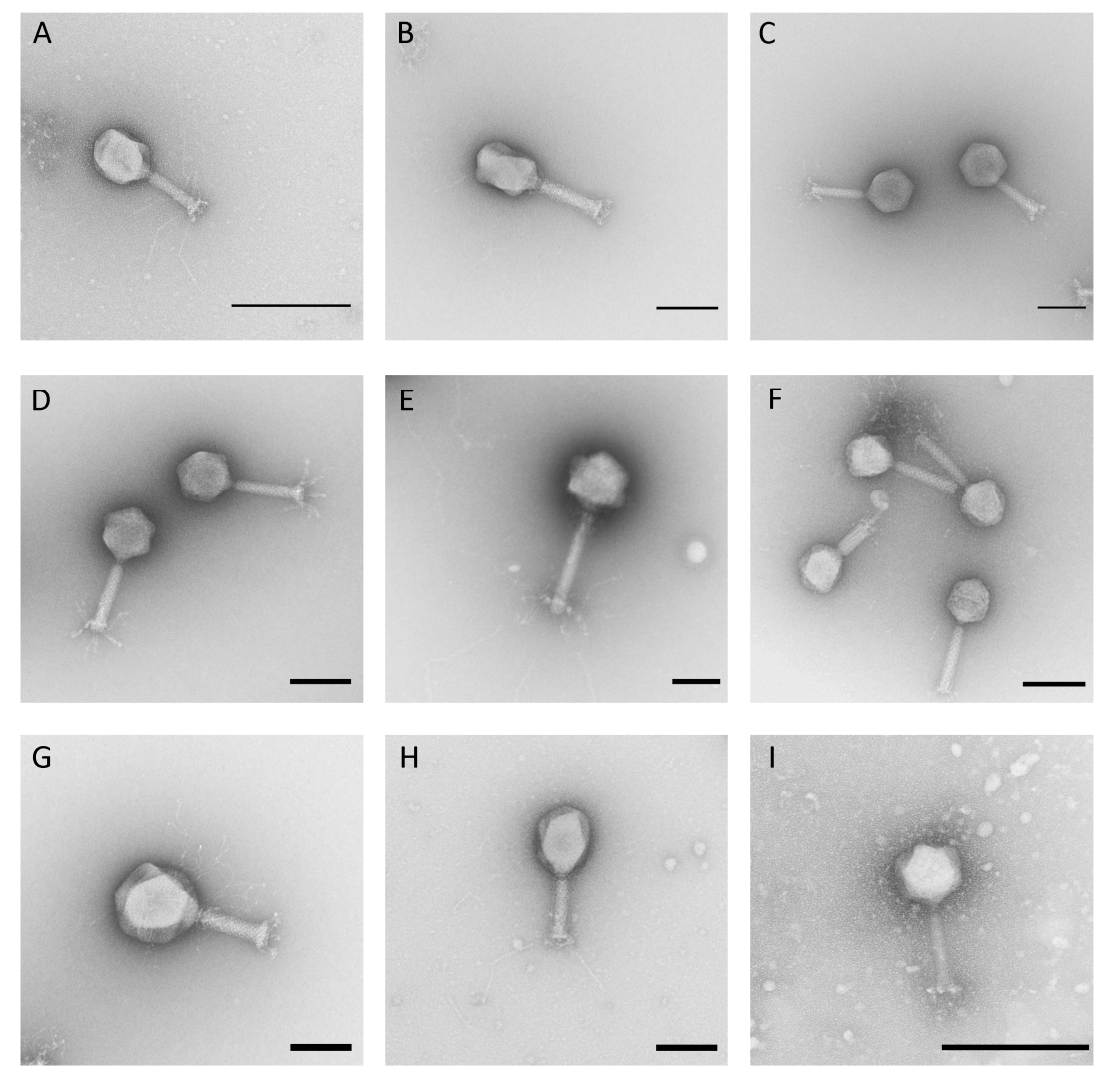

Figure 1. Electron micrographs of isolated phages G53 (A), G50 (B), Schickermooser (C), HdK5 (D), Goslar (E), WFH (F), G17 (G), G4507 (H), and KWBSE43-6 (I) of the myoviruses. Negative staining $(2 \%(w / v)$ uranyl acetate, pH 5.0). Bars represent $100 \mathrm{~nm}$, except for A and I (200 nm). 
Table 1. Morphological analysis of isolated phages.

\begin{tabular}{|c|c|c|c|c|c|}
\hline Morphotype & Phage & $\begin{array}{l}\text { Head Width } \\
(\mathrm{nm})\end{array}$ & $\begin{array}{l}\text { Head Length } \\
(\mathrm{nm})\end{array}$ & $\begin{array}{l}\text { Tail Length } \\
(\mathrm{nm})\end{array}$ & $\begin{array}{l}\text { Classification Based on } \\
\text { Head Length/Width Ratio }\end{array}$ \\
\hline \multirow{11}{*}{ Siphoviruses } & vB_EcoS_HASG4 & $76 \pm 2$ & $79 \pm 3$ & $183 \pm 19$ & B1 \\
\hline & vB_EcoS_EASG3 & $79 \pm 3$ & $80 \pm 7$ & $199 \pm 39$ & B1 \\
\hline & vB_EcoS_HdH2 & $76 \pm 2$ & $79 \pm 3$ & $199 \pm 11$ & B1 \\
\hline & vB_EcoS_VAH1 & $72 \pm 9$ & $79 \pm 5$ & $193 \pm 45$ & B1 \\
\hline & vB_EcoS_WFIE160 & $61 \pm 1$ & $64 \pm 3$ & $155 \pm 23$ & B1 \\
\hline & vB_EcoS_WF5505 & $60 \pm 1$ & $61 \pm 3$ & $136 \pm 10$ & B1 \\
\hline & vB_EcoS_PTXU06 & $59 \pm 2$ & $64 \pm 2$ & $141 \pm 7$ & B1 \\
\hline & vB_EcoS_MM01 & $61 \pm 2$ & $64 \pm 3$ & $153 \pm 5$ & B1 \\
\hline & vB_EcoS_HDK1 & $58 \pm 4$ & $72 \pm 2$ & $223 \pm 5$ & B2 \\
\hline & vB_EcoS_HdSG1 & $62 \pm 3$ & $79 \pm 3$ & $182 \pm 4$ & B2 \\
\hline & vB_EcoS_G29-2 & $66 \pm 3$ & $69 \pm 3$ & $143 \pm 10$ & B1 \\
\hline \multirow{4}{*}{ Podoviruses } & vB_EcoS_KAW1A4500 & $56 \pm 2$ & $58 \pm 1$ & $10 \pm 1$ & $\mathrm{C} 1$ \\
\hline & vB_EcoP_R4596 & $60 \pm 2$ & $60 \pm 3$ & $11 \pm 1$ & $\mathrm{C} 1$ \\
\hline & vB_EcoP_WFI101126 & $47 \pm 2$ & $144 \pm 3$ & $16 \pm 3$ & $\mathrm{C} 3$ \\
\hline & vB_EcoP_PTXU04 & $79 \pm 1$ & $76 \pm 2$ & $14 \pm 1$ & $\mathrm{C} 1$ \\
\hline \multirow{35}{*}{ Myoviruses } & vB_EcoM_Goslar & $124 \pm 6$ & $123 \pm 7$ & $213 \pm 9$ & A1 \\
\hline & vB_EcoM_KWBSE43-6 & $85 \pm 5$ & $93 \pm 4$ & $108 \pm 4$ & A1 \\
\hline & vB_EcoM_Schickermooser & $82 \pm 1$ & $88 \pm 11$ & $102 \pm 9$ & $\mathrm{~A} 1$ \\
\hline & vB_EcoM_WFC & $73 \pm 3$ & $79 \pm 5$ & $110 \pm 4$ & $\mathrm{~A} 1$ \\
\hline & vB_EcoM_WFH & $71 \pm 4$ & $79 \pm 4$ & $111 \pm 2$ & A1 \\
\hline & vB_EcoM_EdH4 & $79 \pm 5$ & $81 \pm 6$ & $112 \pm 1$ & $\mathrm{~A} 1$ \\
\hline & vB_EcoM_HdK5 & $80 \pm 4$ & $88 \pm 4$ & $108 \pm 2$ & $\mathrm{~A} 1$ \\
\hline & vB_EcoM_G17 & $129 \pm 12$ & $139 \pm 4$ & $117 \pm 4$ & $\mathrm{~A} 1$ \\
\hline & vB_EcoM_G29 & $91 \pm 4$ & $120 \pm 7$ & $110 \pm 2$ & $\mathrm{~A} 2$ \\
\hline & vB_EcoM_G9062 & $89 \pm 2$ & $118 \pm 6$ & $106 \pm 4$ & $\mathrm{~A} 2$ \\
\hline & vB_EcoM_G4500 & $90 \pm 4$ & $117 \pm 5$ & $107 \pm 2$ & $\mathrm{~A} 2$ \\
\hline & vB_EcoM_OE5505 & $79 \pm 4$ & $106 \pm 5$ & $104 \pm 6$ & $\mathrm{~A} 2$ \\
\hline & vB_EcoM_D5505 & $87 \pm 7$ & $108 \pm 5$ & $102 \pm 7$ & A2 \\
\hline & vB_EcoM_G4498 & $87 \pm 4$ & $112 \pm 3$ & $105 \pm 3$ & $\mathrm{~A} 2$ \\
\hline & vB_EcoM_G2540 & $91 \pm 3$ & $119 \pm 3$ & $110 \pm 3$ & $\mathrm{~A} 2$ \\
\hline & vB_EcoM_G2540-3 & $82 \pm 4$ & $112 \pm 3$ & $110 \pm 3$ & A2 \\
\hline & vB_EcoM_G8 & $86 \pm 6$ & $115 \pm 4$ & $104 \pm 2$ & A2 \\
\hline & vB_EcoM_G10400 & $84 \pm 6$ & $116 \pm 4$ & $109 \pm 3$ & $\mathrm{~A} 2$ \\
\hline & vB_EcoM_G4507 & $82 \pm 5$ & $114 \pm 6$ & $107 \pm 4$ & $\mathrm{~A} 2$ \\
\hline & vB_EcoM_G2133 & $85 \pm 4$ & $114 \pm 5$ & $105 \pm 4$ & $\mathrm{~A} 2$ \\
\hline & vB_EcoM_G50 & $86 \pm 7$ & $114 \pm 3$ & $100 \pm 6$ & $\mathrm{~A} 2$ \\
\hline & vB_EcoM_R5505 & $83 \pm 4$ & $105 \pm 5$ & $104 \pm 6$ & $\mathrm{~A} 2$ \\
\hline & vB_EcoM_KAW1E185 & $84 \pm 5$ & $116 \pm 4$ & $107 \pm 4$ & $\mathrm{~A} 2$ \\
\hline & vB_EcoM_WFK & $85 \pm 4$ & $112 \pm 4$ & $104 \pm 9$ & $\mathrm{~A} 2$ \\
\hline & vB_EcoM_WFL6982 & $86 \pm 7$ & $113 \pm 5$ & $106 \pm 2$ & $\mathrm{~A} 2$ \\
\hline & vB_EcoM_G2285 & $84 \pm 5$ & $114 \pm 7$ & $111 \pm 5$ & $\mathrm{~A} 2$ \\
\hline & vB_EcoM_G2469 & $88 \pm 4$ & $111 \pm 6$ & $108 \pm 3$ & $\mathrm{~A} 2$ \\
\hline & vB_EcoM_KAW3E185 & $86 \pm 2$ & $113 \pm 4$ & $99 \pm 8$ & $\mathrm{~A} 2$ \\
\hline & vB_EcoM_WFbE185 & $85 \pm 5$ & $116 \pm 8$ & $104 \pm 3$ & $\mathrm{~A} 2$ \\
\hline & vB_EcoM_MM02 & $90 \pm 6$ & $112 \pm 5$ & $108 \pm 8$ & $\mathrm{~A} 2$ \\
\hline & vB_EcoM_G53 & $85 \pm 1$ & $109 \pm 12$ & $102 \pm 8$ & $\mathrm{~A} 2$ \\
\hline & vB_EcoM_G5211 & $84 \pm 3$ & $114 \pm 3$ & $110 \pm 6$ & $\mathrm{~A} 2$ \\
\hline & vB_EcoM_G2248 & $80 \pm 2$ & $109 \pm 8$ & $104 \pm 4$ & A2 \\
\hline & vB_EcoM_G2494 & $82 \pm 2$ & $115 \pm 1$ & $113 \pm 4$ & $\mathrm{~A} 2$ \\
\hline & vB_EcoM_G37-3 & $78 \pm 3$ & $108 \pm 2$ & $110 \pm 3$ & A2 \\
\hline
\end{tabular}



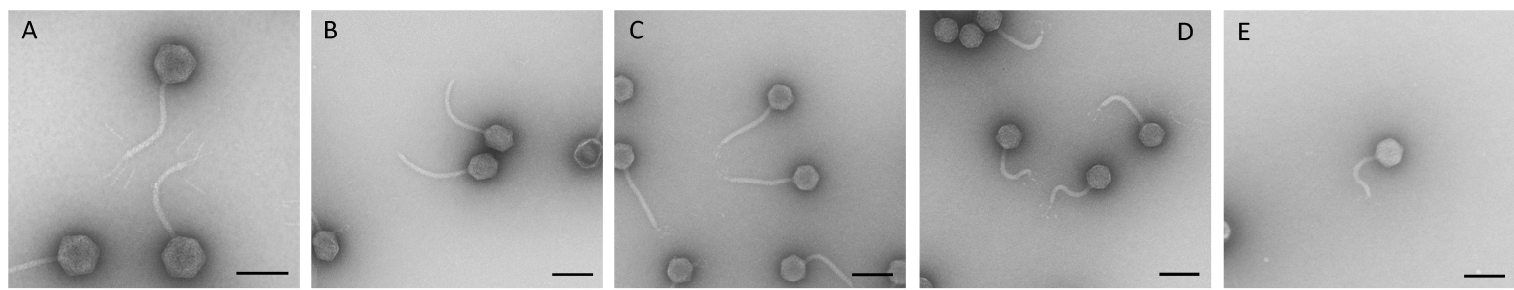

Figure 2. Electron micrographs of isolated phages HASG4 (A), HdK1 (B), MM01 (C), PTXU06 (D), and G29-2 (E) of the siphoviruses family. Negative staining ( $2 \%(w / v)$ uranyl acetate, $\mathrm{pH} 5.0)$. Bars represent $100 \mathrm{~nm}$.
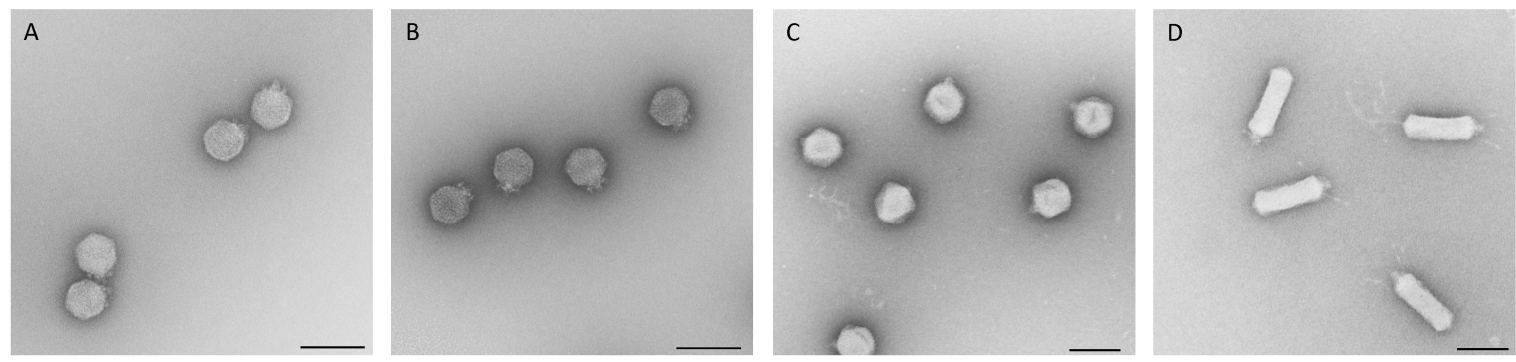

Figure 3. Electron micrographs of isolated phages KAW1A4500 (A), R4596 (B), PTXU04 (C), and WFI101126 (D) of the podoviruses. Negative staining ( $2 \%(w / v)$ uranyl acetate, $\mathrm{pH} 5.0)$. Bars represent $100 \mathrm{~nm}$.

\subsection{Host Spectrum}

Altogether, 50 phages were isolated from various habitats, such as surface water, wastewater, manure, or animal feces. The host range of these phages was performed in a qualitative approach by spotting serial dilutions on double agar plates containing potential host cells. Host strains were classified as sensitive when single plaques were generally detected at any dilution. All of them were tested against a set of $64 \mathrm{E}$. coli strains from different origins, e.g., ESBL-producing E. coli or avian pathogenic E. coli, representing different serotypes. Finally, each E. coli strain was lysed by at least one of the phages isolated in this study (Figure 4). Phages showed very diverse lytic behavior, ranging from very specifically lysing only one bacterial strain of this set to infecting and lysing nearly $55 \%$ of the tested strains. In particular, members of the Podoviridae family revealed a very narrow host range with R4596 and WFI101126 forming plaques only on one specific strain. In contrast, some myoviruses, such as WFH and T4-like phages G2540 and G4507, showed a relatively broad host range and lysed more than 25 strains. Regarding the siphoviruses of this study, those phages also showed a rather narrow host range and lysed only up to 11 strains of the examined set. When analyzing the putative serotype-dependent lysis behavior for those phages that lysed more than 10 strains, no such specificity was detected with the exception of WF5505. While myoviruses with a broader host range lysed strains throughout all serotypes, the siphovirus WF5505 lysed only strains that belonged to the serotype O25:H4. 


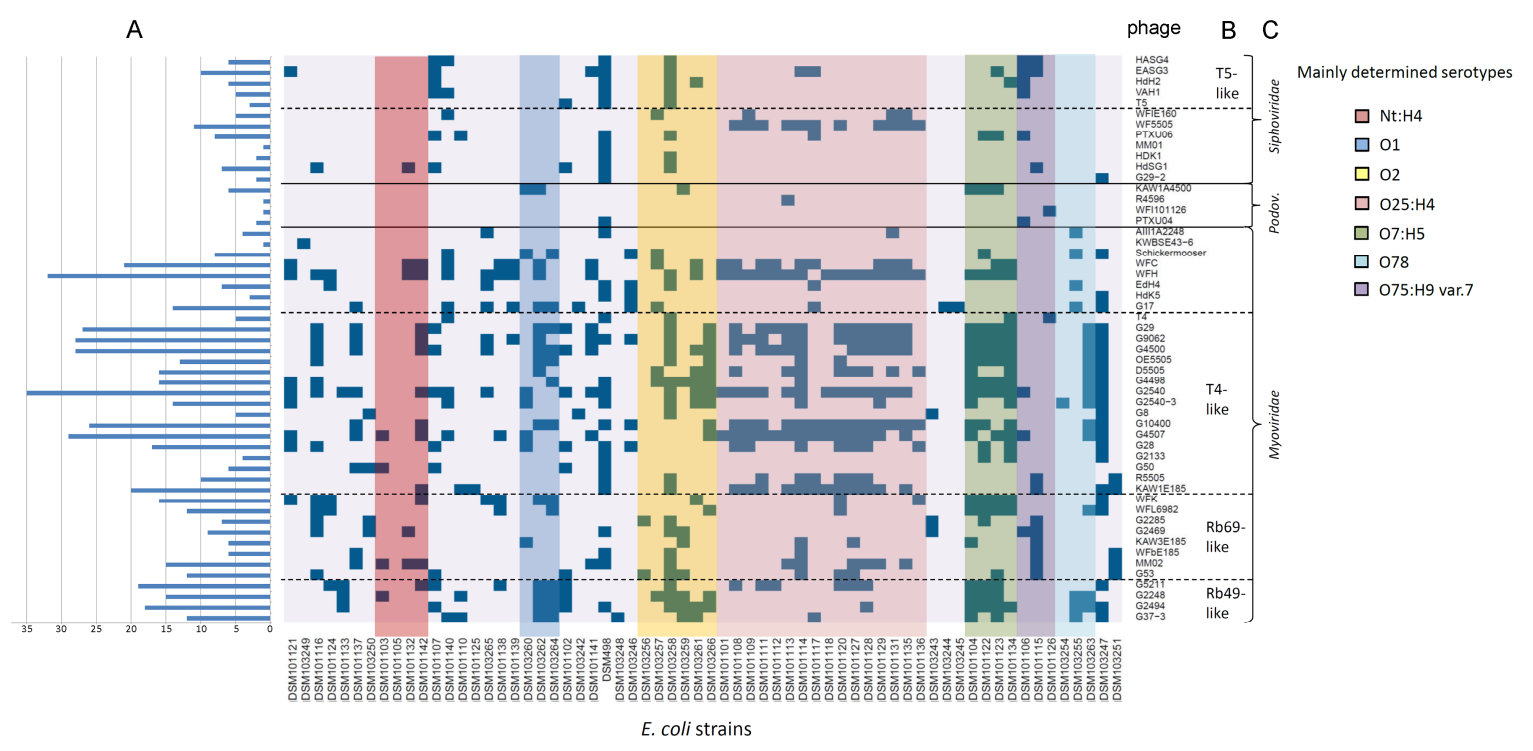

Figure 4. Analysis of the lytic behavior of isolated phages on a set of 64 Escherichia coli strains from various serotypes. Blue squares indicate plaque formation of a given phage. The number of strains that were successfully lysed by a given phage are shown in (A). Order of the phages (y-axis) is based on morphology (C) and taxonomic classification (B), respectively. The order of E. coli strains is based on determined serotypes. As there are many T4-like and T5-like phages in our study, phages T4 and T5 were also included in this analysis.

\subsection{Genomic Analysis of Isolated Podoviruses}

Phage genomes of this study were sequenced using either Illumina or PacBio RS II technology to determine their genome sequence. The assembled sequences were analyzed in particular regarding their relatedness to known phages, taxonomy, and specific features. Generally, phage genome sizes ranged from approximately $71 \mathrm{~kb}$ to $371 \mathrm{~kb}$ (GC content $35.2-46.5 \%$ ) for myoviruses, siphoviruses revealed genomes with sizes between approximately 42 and $125 \mathrm{~kb}$ (GC content 39.0-54.6\%), while the genomes of the isolated podoviruses displayed sizes from approximately $44 \mathrm{up}$ to $77 \mathrm{~kb}$ (GC content $42.0-52.85 \%$ ) (Table S4).

BLASTn analysis to check for related phage genomes and comparison via dot plot analysis using GEPARD [42] of the genomes of four podoviruses isolated in this study (Figure S1) showed that at least one of them, namely PTXU04, did not reveal any similarities to other phages in databases at the nucleotide level in the BLASTn analysis and was considered as novel. The amino-acid-based VICTOR analysis revealed similarities to other phages only between 0 and $1.44 \%$ (see Supplementary Table S5). In contrast, phages KAW1A4500 and R4596 showed VICTOR-based similarities of 73.5\% (R4596) and 90.2\% (KAW1A4500) to phages K1E (GenBank acc. no. AM084415) and similarities of 73.8\% (R4596) and 91.8\% (KAW1A4500) to phage vB_EcoP_C (GenBank acc. no. KY295892) and, therefore, were classified as members of the subfamily Autographivirinae in the VICTOR analysis, given the established threshold for subfamily delineation [36]. Analysis of the genome of phage WFI101126, which displayed a rare C3-like morphology, revealed that WFI101126 has a similarity of $84.6 \%$ (see Supplementary Table S5) to phage phiEco32 (GenBank acc. no. EU330206) and, therefore, belongs to the classified Kuravirus (ICTV document 2018.007B.Av1.rename137gen6sp) according to the VICTOR analysis and the established threshold for genus delineation. The results of the VICTOR analysis revealed maximally supported genus clusters and, thus, provided strong support for the proposed creation of a new genus "Xuquatrovirus" within the Podoviridae family with phage PTXU04 as the "type phage" (Figure 5). Phages WFI101126, R4596, and KAW1A4500 were placed by VICTOR in maximally supported genus clusters matching known ICTV genera (Kuravirus, Teseptimavirus, and Zindervirus, respectively). Whereas VICTOR placed phages R4596 and KAW1A4500 as members of the 
Zindervirus in the known ICTV subfamily Autographivirinae, phages PTXU04 and WFI101126 represent two novel, also maximally supported subfamilies (Figure 5).

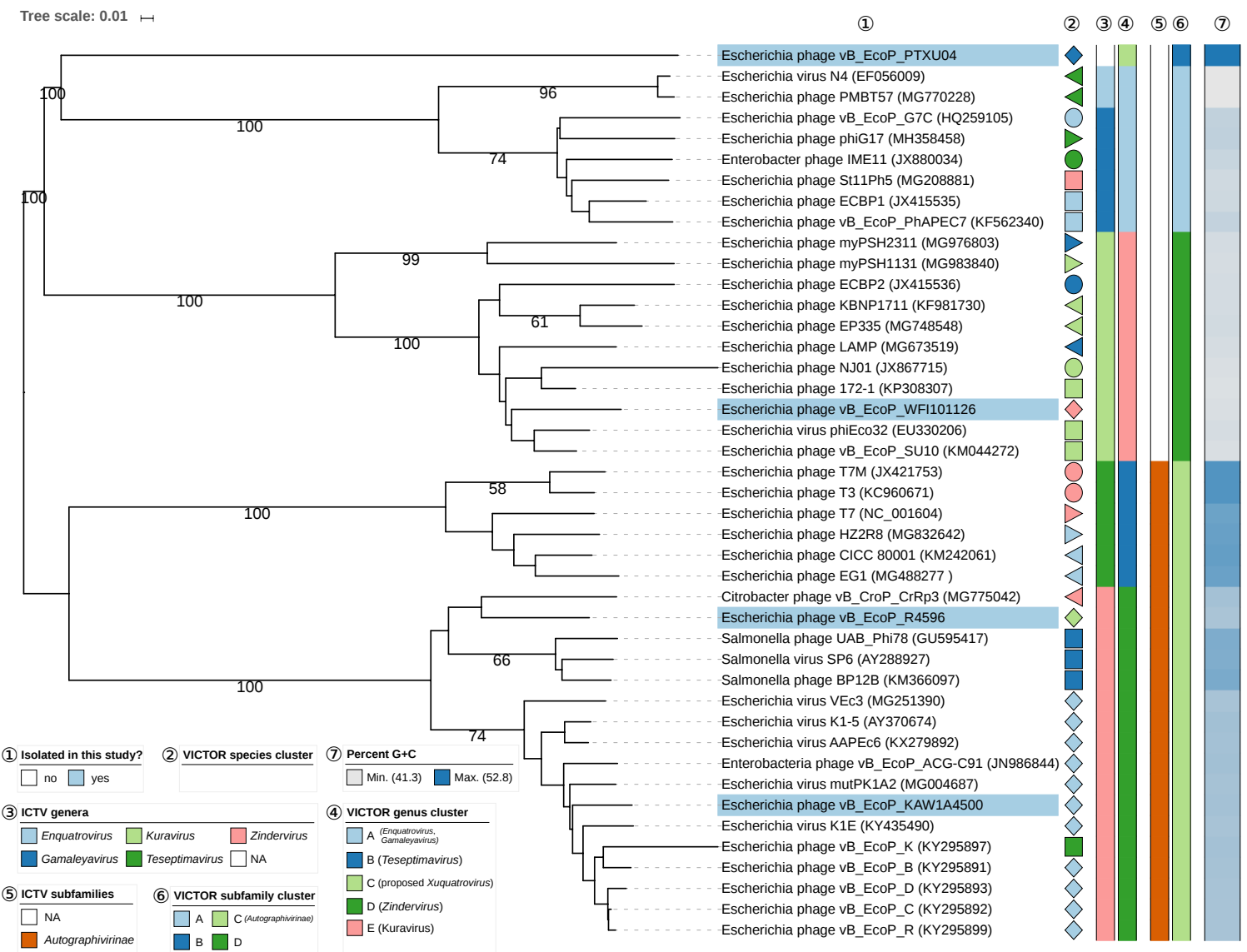

Figure 5. Phylogenomic analysis of Podoviridae members of this study at the amino acid level using VICTOR. The recommended VICTOR tree (formula $d_{6}$ ) is shown and the numbers shown above the branches are Genome-BLAST Distance Phylogeny (GBDP) pseudo-bootstrap support values from 100 replications, given that branch support exceeds 50\%. The branch lengths of the resulting VICTOR trees are scaled in terms of the used distance formula. Annotations are given to the right-hand side of the tree: indicator for newly isolated phages (1), genera and subfamilies according to International Committee on Taxonomy of Viruses (ICTV) $(3,5)$, species, genus, and subfamily cluster proposed by $\operatorname{VICTOR}(2,4,6)$, and genomic G+C content $(7)$.

\subsection{Genomic Analysis of Isolated Siphoviruses}

Similar to the analysis of the isolated podoviruses, we also performed a BLASTn and subsequent dot plot analysis of the genomes of different siphoviruses with GEPARD (Figure S2). Three phages in our study (WFIE160, PTXU06, and WF5505) showed a high level of synteny compared to, e.g., phages slur05 and EK99P-1 (GenBank acc. nos. LN881730 and KM233151, respectively) amongst others at the nucleotide level and, therefore, were classified to the genus Dhillonvirus. Because of their high degree of relatedness to phages T5 or FFH1 (GenBank acc. no. AY543070 and KJ190157, respectively), phages VAH1, EASG3, HASG4, and HdH2 are considered to be new members of the Tequintavirus. Two further phages of our study, phages HdSG1 and HdK1, were identified that belong to the Nonagvirus, a group of phages like phage 9g [43] or JenP1 (GenBank acc. no. KJ419279 and KP719132, respectively) harboring specific gene clusters for queuosine synthesis. While analysis of phage MM01 grouped it into the Tunavirinae subfamily, phage G29-2 showed the highest VICTOR similarity $(88.5 \%$; see Supplementary Table S5) to Shigella phage pSF-1, which is still unclassified. 


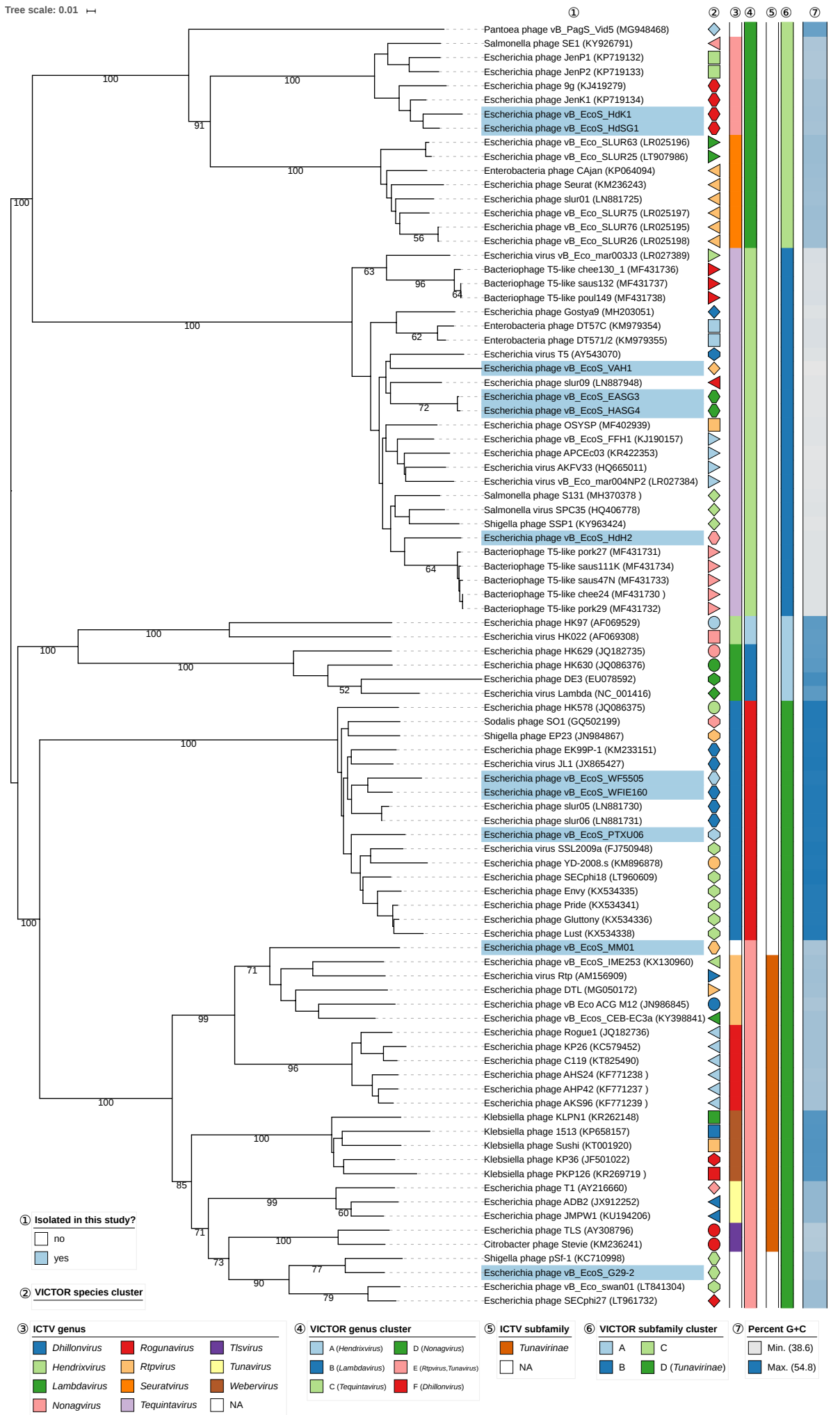

Figure 6. Phylogenomic analysis of Siphoviridae members of this study at the amino acid level using VICTOR. The recommended VICTOR tree (formula $d_{6}$ ) is shown and the numbers listed above the branches are GBDP pseudo-bootstrap support values from 100 replications, given that branch support exceeds $50 \%$. The branch lengths of the resulting VICTOR trees are scaled in terms of the used distance formula. Annotations are given to the right-hand side of the tree: indicator for newly isolated phages (1), genera and subfamilies according to ICTV $(3,5)$, species, genus, and subfamily cluster proposed by $\operatorname{VICTOR}(2,4,6)$, and genomic G+C content $(7)$. 
In regard to the amino-acid-based VICTOR analysis of the siphovirus dataset (Figure 6), all genus clusters were in congruence with the current ICTV genus classification except for genus cluster " $\mathrm{E}$ ", which included both Rtpvirus and Tunavirus. Since VICTOR is optimized against the ICTV classification, this deviation indicates that the existing classification into these two particular genera might be too fine-grained and could be merged into a single ICTV genus as represented by VICTOR cluster " $E$ ", that way including the newly isolated phages MM01 and G29-2. That way, the resulting genera would also be more uniform in terms of sequence divergence, an important criterion of any classification. The classification at the subfamily level revealed that phages MM01, G29-2, WF5505, WFIE160, and PTXU06 can safely be assigned to the Tunavirinae, whereas two new subfamilies can be proposed for phages HdK1 and HdSG1 (subfamily cluster " $\mathrm{C}$ ") and phages VAH1, HdH2, EASG3, and HASG4 (subfamily cluster "B").

\subsection{Genomic Analysis of Isolated Myoviruses}

All genomes of the isolated myoviruses of this study were analyzed with BLASTn and GEPARD to visualize nucleotide sequence similarity (Figure S3) complemented by an amino-acid-based VICTOR analysis of the coding regions (Figure 7). Based on those results, the majority of the analyzed myoviruses were placed in the large subfamily Tevenvirinae with members distributed over the genera Krischvirus, Gaprivervirus, Dhakavirus, Mosigvirus, and Tequatrovirus.

Two phages, EdH4 and HdK5, showed high VICTOR similarities (>93\%) to Escherichia phages Murica and FFH2 (GenBank acc. no. KT001917 and KJ190158, respectively), all of them placed in genus cluster " $\mathrm{D}$ " (Figure 7) and, therefore, identified as members of Vequintavirus. Other currently unclassified phages were located in distinct VICTOR genus clusters without affiliation to known ICTV genera, i.e., phages Goslar, WFC, WFH, Schickermooser, and KWBSE43-6. Phages WFC and WFH form a species cluster together with phages ECML-117 and FEC19 belonging to a single genus cluster " $F$ " that we tend to call "Wifcevirus", while phage Schickermooser was classified as a member of the VICTOR genus cluster " $A$ " (proposed "Phapecoctavirus") Interestingly, phage KWBSE43-6 is phylogenetically most closely related to a maximally supported group of non-E. coli phages (genus

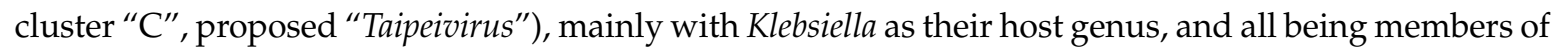
the Tevenvirinae (Figure 7). Phage Goslar is the only myovirus of this study that showed no nucleotide sequence similarity to any known phage after BLASTn analysis. Therefore, we propose to create a new genus within the Myoviridae, namely "Goslarvirus". VICTOR strongly supports the proposal of new subfamilies for subfamily clusters " $\mathrm{E}$ " (including phage G17), " $\mathrm{D}$ " (including phages WFC and WFH), and "B" (phage Goslar). 


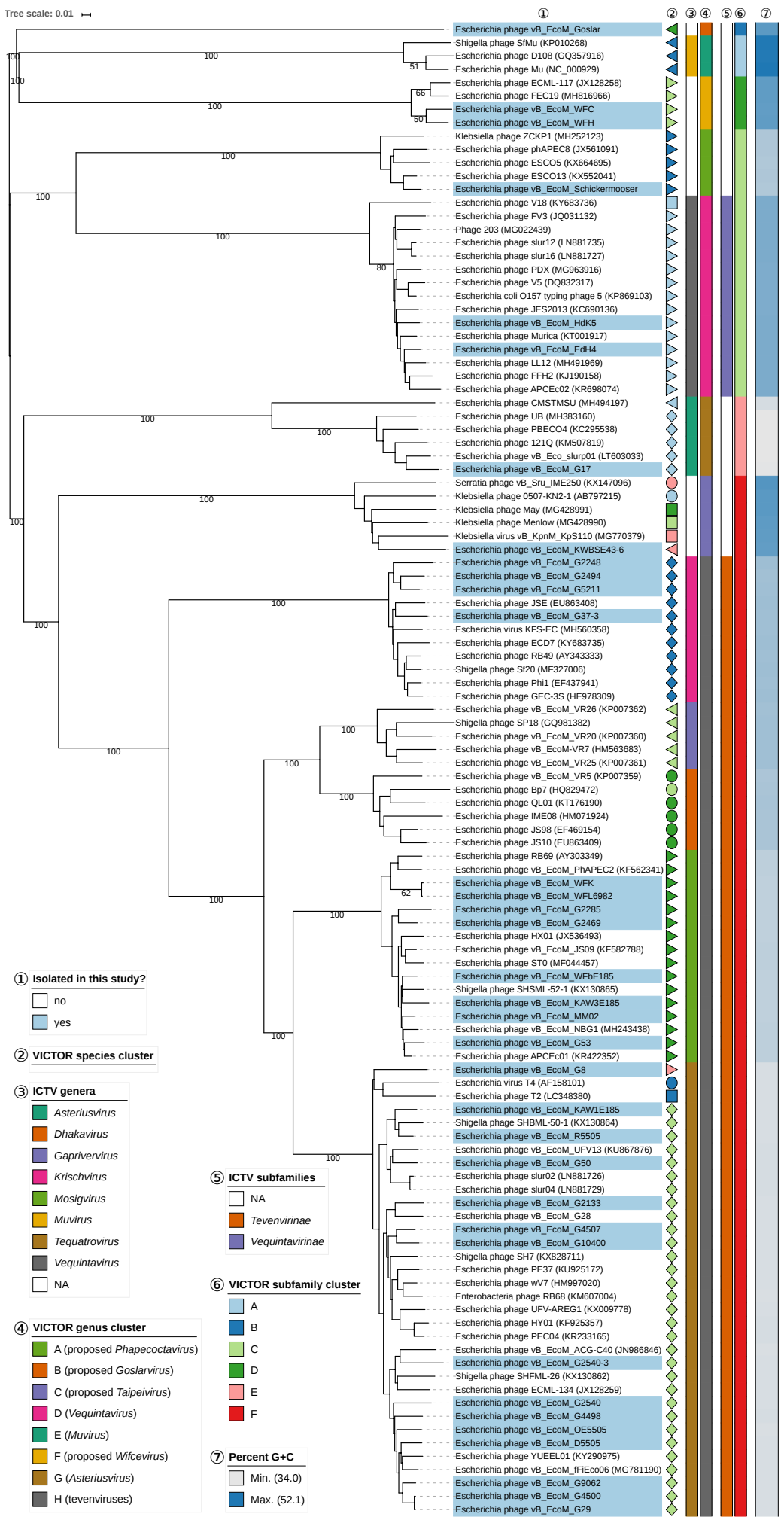

Figure 7. Phylogenomic analysis of Myoviridae members of this study at the amino acid level using VICTOR. The recommended VICTOR tree (formula $d_{6}$ ) is shown and the numbers above branches are GBDP pseudo-bootstrap support values from 100 replications, given that branch support exceeds 50\%. The branch lengths of the resulting VICTOR trees are scaled in terms of the used distance formula. Annotations are given to the right-hand side of the tree: indicator for newly isolated phages (1), genera and subfamilies according to ICTV $(3,5)$, species, genus, and subfamily cluster proposed by VICTOR $(2,4,6)$, and genomic $\mathrm{G}+\mathrm{C}$ content $(7)$. 


\subsection{Genomic Analysis of Genomic Singleton Phages}

\subsubsection{Phage PTXU04}

Phage PTXU04 revealed a total genome size of 61,600 bp (Figure 8) (GenBank acc. no. MK373772). Time-limited exonuclease treatment of its genomic DNA, followed by hydrolysis with restriction enzymes, also indicated that its genome is not circularly permuted (Figure S4). Automated followed by subsequent manual curated annotation using Prokka and Artemis revealed 92 coding sequences (CDSs), while no tRNA genes were found. Based on conserved domains detected in the deduced amino acid sequences and only weak similarities to annotated genes in GenBank followed by a search against the pVOG database, some essential genes were identified, leading to a grouping of genes into characteristic gene clusters similar to those involved in head and tail morphogenesis, lysis, or replication. Thus, we identified domains, e.g., for the terminase subunit (locus tag PTXU04_00002, PHA02533), a major capsid protein (PTXU04_00010, TIGR04387), a putative NTP-PPase (PTXU04_00033, cd11542), DNA polymerase (PTXU04_00035, cd05538), helicase (PTXU04_00041, COG1061), a primase (PTXU04_00044, TIGR01613), and a putative DNA N-6-adenine-methyltransferase (Dam) (PTXU04_00045, pfam05869).

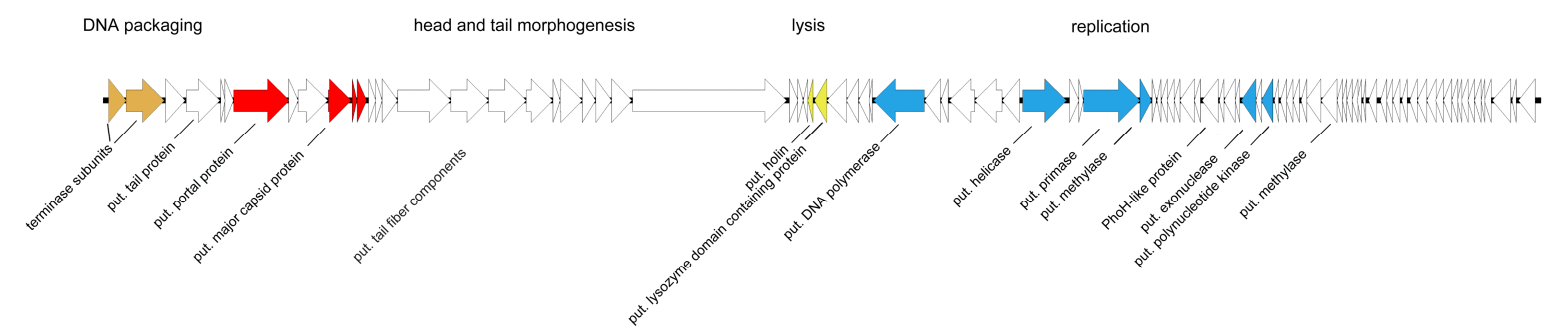

Figure 8. Genomic organization of PTXU04. Genes for identified structural proteins using peptide mass fingerprinting are marked in red, putative genes for DNA packaging in orange, putative genes for lysis in yellow, and genes involved in replication in blue (put. = putative).

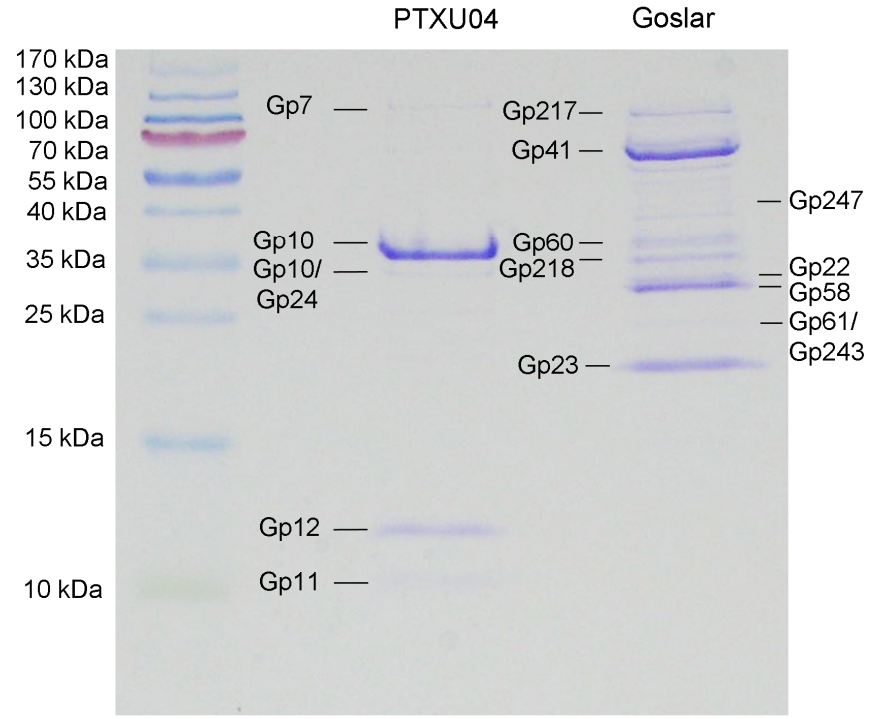

Figure 9. SDS-PAGE profile of structural proteins of phages PTXU04 and Goslar and identification via mass peptide fingerprinting. Proteins were separated by $15 \%$ SDS-PAGE. After extraction of gel bands and tryptic digestion, samples were analyzed via peptide mass fingerprinting. Identified gene products are shown.

Since comparison of the genome sequence of PTXU04 with other phages in GenBank via BLASTn (against taxid:28883) resulted in no hits and BLASTp analysis revealed only weak similarities to known phages or conserved gene products, we used mass peptide fingerprinting to obtain hints on 
the location of some structural genes in the genome and to verify putative annotations. Therefore, phage particles were denatured by boiling and separated by SDS-PAGE (Figure 9). Afterwards, several protein bands were extracted and identified by peptide mass fingerprinting (Table S6). Finally, four bands were clearly assigned to genes of PTXU04, namely gp7 (PTXU04_00007), gp10 (PTXU04_00010), gp11 (PTXU04_00011), and gp12 (PTXU04_00012) (Figure 8). The most prominent band could be identified as the major capsid protein $(g p 10)$.

\subsubsection{Phage Goslar}

Sequencing of phage Goslar resulted in a genome size of 237,307 bp (GC content of 46.53\%), classifying it as a jumbo phage. In this case, treatment with exonuclease BAL-31 and subsequent hydrolysis with different restriction enzymes showed that the genome of this phage appears to be circularly permuted. Annotation led to the determination of 249 predicted CDS, but no tRNAs (Figure 10). Though comparison at the nucleotide level resulted in only a small number of short stretches of similarity to other phages, BLASTP analysis gene by gene and hmmscan using the pVOG database revealed several shared conserved domains and similarities to other phages, so that a rough characterization of the genome organization could be performed. Thus, we identified putative genes involved in replication, e.g., a DNA ligase and helicase, in nucleotide metabolism, e.g., a putative thymidylate synthase, and a chitinase, which may be involved in host lysis. Based on the number of hits in the BLASTP analysis, we chose phages from GenBank for further analysis with CoreGenes3.5 [44,45]. Thus, we identified non-Escherichia phages that shared at least more than 70 homologs with phage Goslar, namely Pseudomonas phages phiKZ (77), PhiPA3 (79), Phabio (77), and Noxifer (84), Erwinia phages vB_EamM_ChrisDB (76), PhiEAH1 (83), and Ea35-70 (91), and Ralstonia phage RSL2 (75).

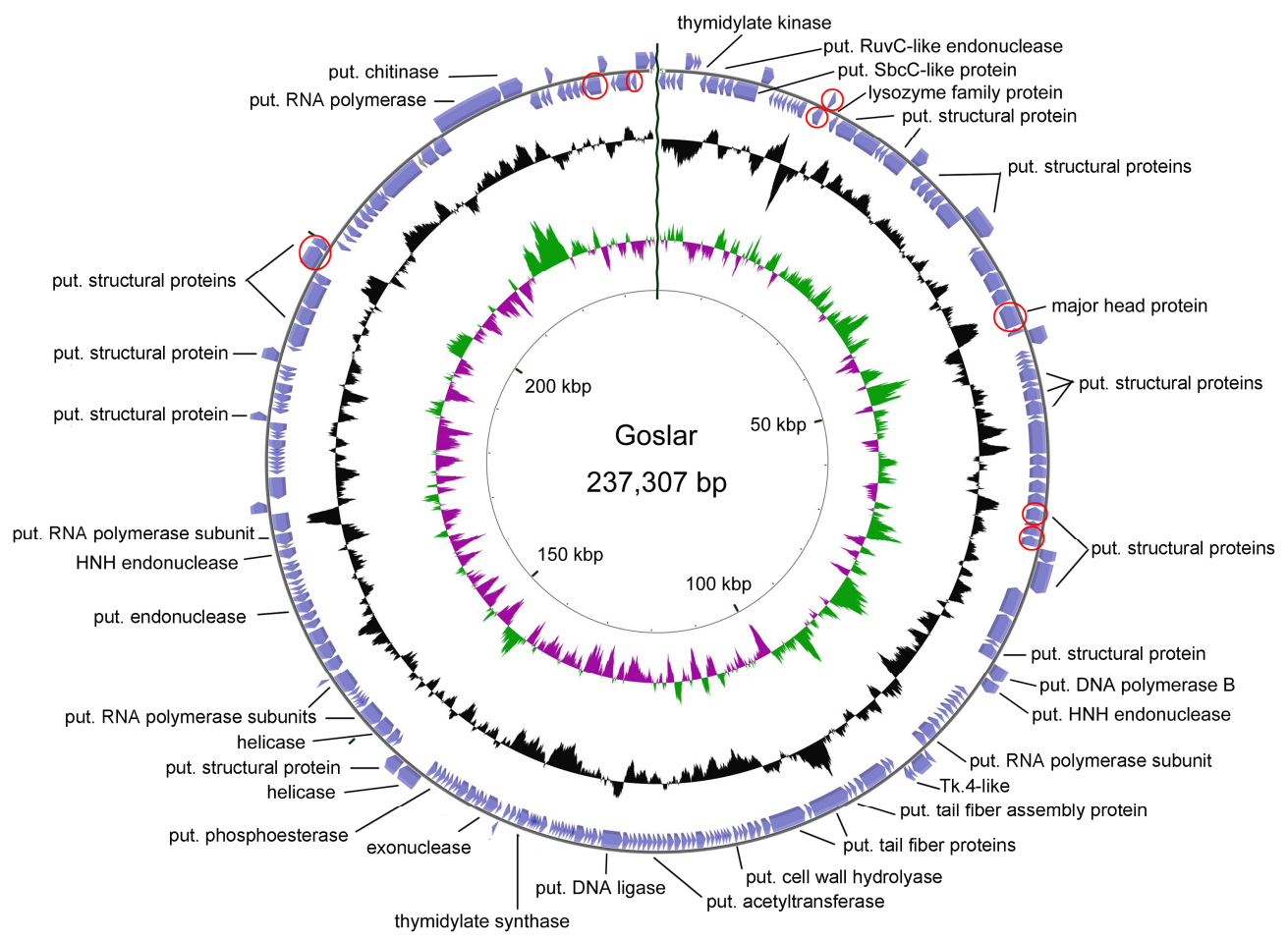

Figure 10. Genomic organization of phage Goslar. Based on its permutation, the genome is visualized in a circular form. Genes for identified structural proteins using peptide mass fingerprinting are marked in red (put. = putative).

In addition, peptide fingerprinting analysis (Figure 9, Table S6) identified 10 genes for structural components that are not located in one cluster, but distributed over the whole genome of Goslar, including the gene for a major capsid protein (Goslar_00041). 


\subsection{Grouping of Isolated Phages into Already Classified Genera}

\subsubsection{Phieco32-Like Viruses}

Based on their striking C3-like morphological features displaying elongated capsids at first hand and also on genomic and proteomic approaches, the genus Kuravirus was created by the ICTV and consists currently of six officially classified members (Figure 9), including already published phages phiEco32 [41], vB_EcoP_SU10 [40], NJ01 [46], and ECBP2 [47]. Generally, after our analysis, all suggested members had a genome size of about $77 \mathrm{~kb}$ (average GC content $42.2 \%$ ), encoded about 74 proteins, and revealed 0-1 tRNAs with the exception of phages LAMP (MG673519) and myPSH2311 (MG976803), which have smaller genomes of about $68.6 \mathrm{~kb}$. Overall, the ends of the WFI101126 genome were adjusted based on PhiEco32 and vB_EcoP_SU10, which revealed the strongest similarities (VICTOR similarity of 92.1\%; see Supplementary Table S5). A synteny plot of different kuraviruses (Figure 11) showed that they all have nearly the same genome organization apart from small differences. One major difference of WFI101126 is the organization of the cluster for putative tail fibers. While all other phiEco32-like phages seem to have several genes encoding tail-fiber-associated proteins, WFI101126 seems to harbor one less (WFI101126_0001212, marked in blue). Altogether, our analysis of WFI101126 isolated in this study compared to other related phages clearly classified it and four other phages as members of this distinct genus.

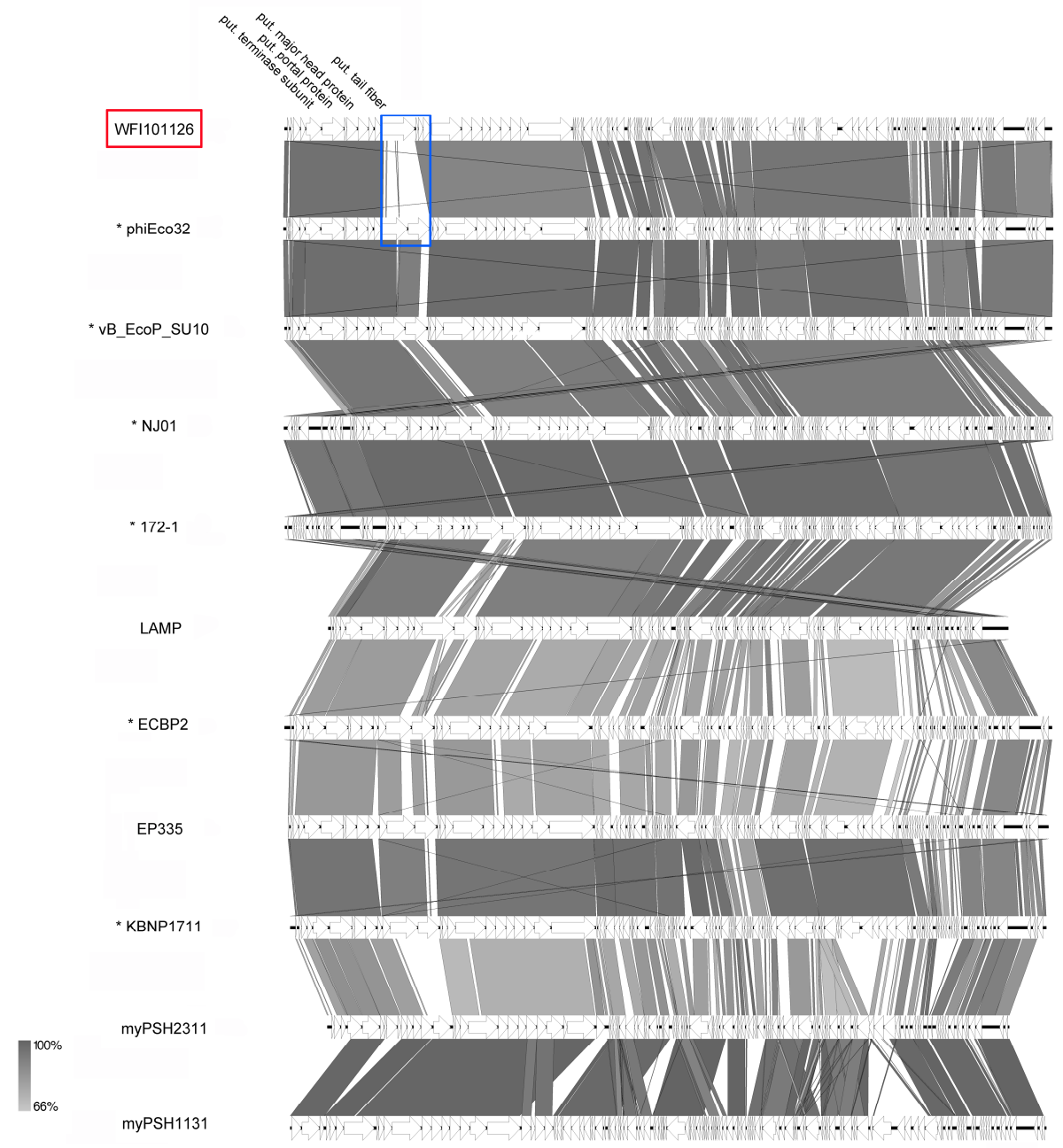

Figure 11. Synteny plot of phage WFI101126 compared to other kuraviruses at the nucleotide level (pairwise comparison with the genome next to it on the figure). The figure was generated with EasyFig [48]. Asterisks indicate official classification as the genus Kuravirus is already recognized by ICTV. Isolates of this study are marked in red. 


\subsubsection{Sp6-Like Viruses}

In this study, we isolated two podoviruses that revealed icosahedral heads and short tails. After sequencing and genome analysis, they were found to be similar to SP6 [49], two capsular-specific phages [50], and a set of other E. coli phages from a historic collection [51] with respect to their genome organization. Genome sizes ranged from 37.7 to $45.2 \mathrm{~kb}$ with an average GC content of $45.5 \%$. As with other SP6-like phages, none harbored a tRNA gene. As described for some SP6-like phages [51], we also detected short terminal repeats of $266 \mathrm{bp}$ and $428 \mathrm{bp}$ for KAW1A4500 and R4596, respectively. While phage KAW1A4500 was similar to capsular-specific phages K1E and K1-5 (VICTOR similarity of c. 90\%; see Supplementary Table S5) and other Escherichia phages of that genus, R4596 tends to cluster with phages with Salmonella as their host organism, such as phage UAB_Phi78 (Figure 10). Though very similarly organized, their genome structure revealed some differences, in particular in the gene cluster for enzymes putatively involved in lysis (Figure 12). The gene cluster identified in KAW1A4500 seems to be conserved among its closest relatives apart from an additional gene (KAW1A4500_00051), which was only identified in phage mutPK1A2 (mutPK1A2_p54) as well. Interestingly, phages K1-5 and AAPEc6 additionally harbored a gene encoding a putative lyase (conserved domain Peptidase_S74 pfam13884) separated from the conserved endosialidase gene (conserved domains pfam12217-19). In comparison, Salmonella phage UAB_Phi78, SP6, and BP12B possessed two genes in this region, one encoding a P22-like tail-spike (pfam09251). Analysis of this region in the genome of phage R4596 showed that it carried an additional gene (R4596rev_00038) upstream in the structural gene cluster that does not appear in all other genomes. Its gene product revealed a conserved domain (pfam03906) for a T7-like tail fiber structure. Apart from that, R4596 did not show any sign of an endosialidase gene, but one gene for a putative pectate lyase (pfam12708) (R4596rev_00049).

\subsubsection{T5-Like Viruses}

Several new T5-like phages have been isolated from different habitats and studied in recent studies $[19,20]$. In our study, we also identified four phages closely related to Escherichia phage T5. All of them were isolated from samples associated with different birds. While phages HdH2 and HASG4 were identified using chicken feces, phages EASG3 and VAH1 were isolated from duck and budgie droppings, respectively. In regard to their sequence, the genome sizes ranged between 120 and $124 \mathrm{~kb}$, displaying the characteristic T5-like terminal repeats of about 10-11 kb and 21-24 tRNA genes. Major differences were again detected in the region for genes involved in adsorption, in particular in the gene for the L-shaped tail fiber of T5, which is exchanged in the other phages (Figure 13, marked in blue). While the homolog in EASG3 and HASG4 revealed similarities to a tail fiber gene from Salmonella phage SP1a, HdH2 harbored two genes for tail-fiber-like proteins similar to Salmonella phage Sw2. Further differences were also identified in the gene for the T5 straight tail fiber (T5.140) and the receptor binding protein (T5.157), which might be the reason for different host ranges of the T5-like phages of our study. 


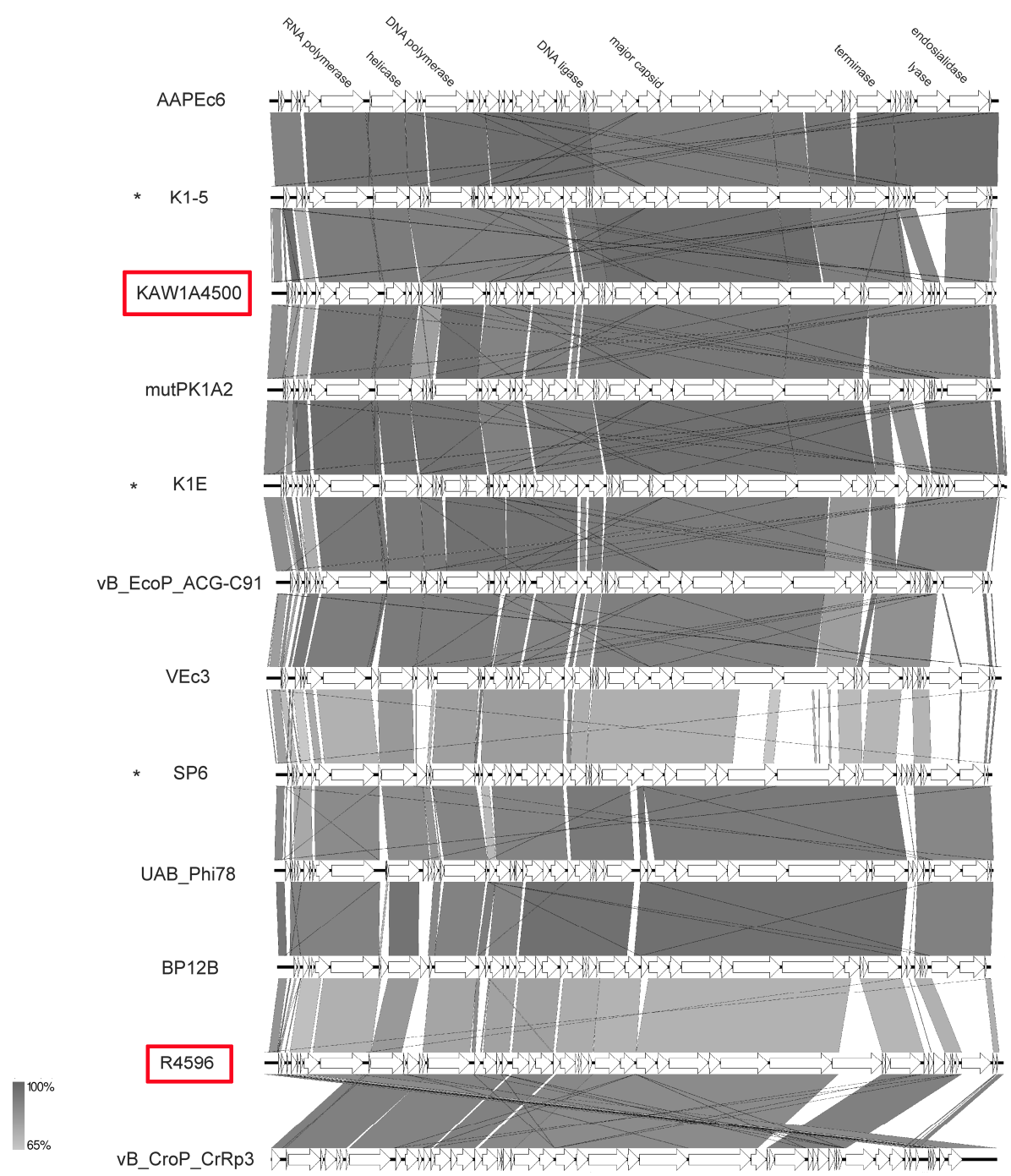

Figure 12. Genomic organization of phages R4596 and KAW1A4500 compared to selected zinderviruses at the nucleotide level. The figure was generated with EasyFig [48]. Asterisks indicate official classification as Zindervirus already ratified by ICTV. Isolates of this study are marked in red.

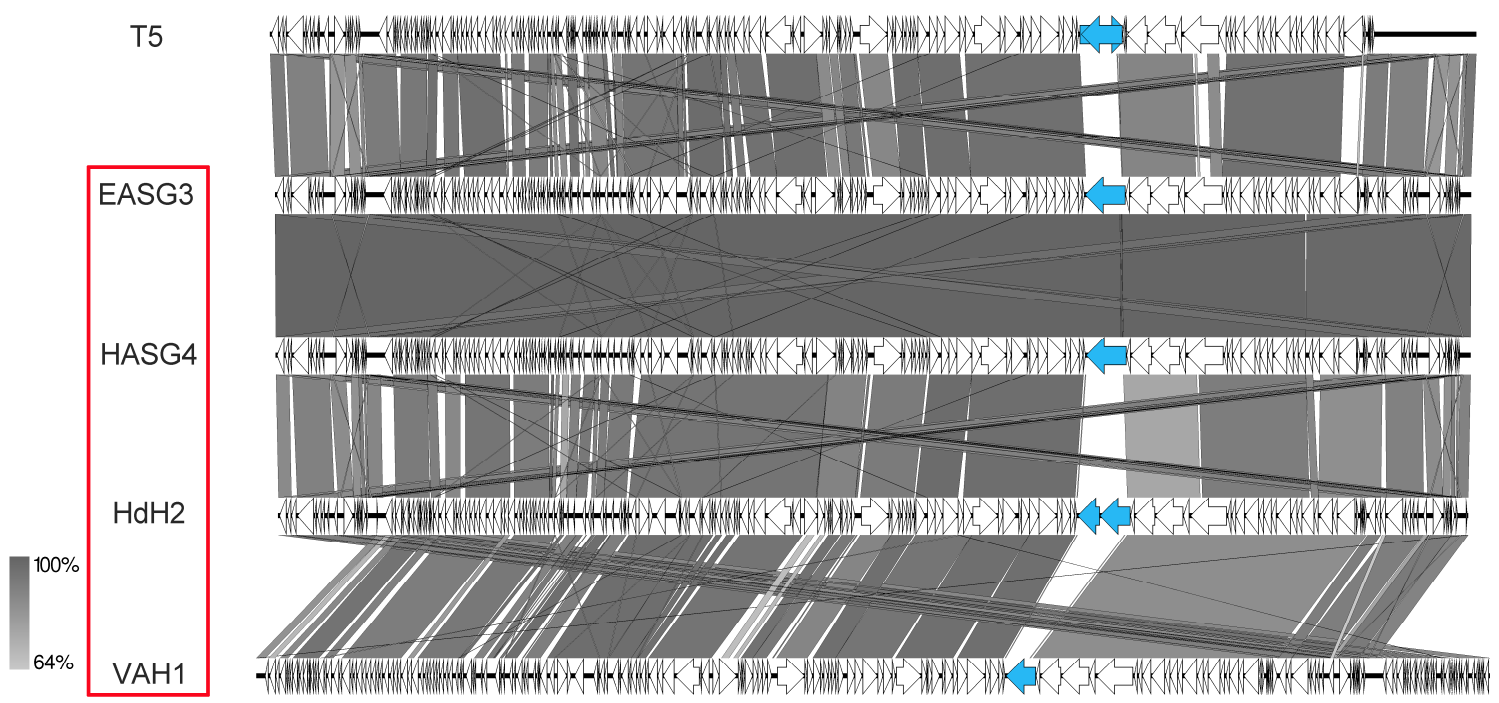

Figure 13. Genomic organization of T5-like phages of this study compared to phage T5 at the nucleotide level. The figure was generated with EasyFig. Isolates of this study are marked in red. 


\subsubsection{9g-Like Viruses}

Two siphoviruses of our study, namely HdK1 and HdSG1, that were isolated from chicken dung revealed high VICTOR similarities $>86.4 \%$ (see Supplementary Table S5) to phage $9 \mathrm{~g}$ and phages belonging to the Nonagvirus genus. However, a few differences were detected. As already described for other phage groups of this study, those differences were mainly detected in the cluster for putative tail fibers or other gene products involved in adsorption (Figure 14). So far, five similar phages (Salmonella phage SE1 and Escherichia phages 9g, Jenk1, JenP1, and JenP2) isolated from fecal matters are described in the literature displaying the same genomic organization as HDK1 or HdSG1 [43,52]. Altogether, their genome sizes range from 56.7 to $64 \mathrm{~kb}$ with an average GC content of $43.6 \%$. The main identifiable characteristic of the genera Nonagvirus and Seuratvirus is the presence of a queuosine synthesis cluster [53, 54]. In phage $\mathrm{HdK} 1$, this cluster contains genes for a putative queuosine tRNA-ribosyltransferase similar to that of phage $9 \mathrm{~g}$ (HdK1rev_00055), a putative queuosine biosynthesis protein FolE (conserved domain FolE COG0302 GTP cyclohydrolase I) (HdK1rev_00056), a putative 6-carboxy-5,6,7,8-tetrahydropterin synthase (conserved domain queuosine_QueD TIGR03367) (HdK1rev_00057), a putative queuosine biosynthesis QueC ATPase (conserved domain QueC COG0603 7-cyano-7-deazaguanine synthase) (HdK1rev_00058), and a putative queuosine biosynthesis QueE (conserved domain NrdG COG0602) (HdK1rev_00060) identical to Enterobacteria phage JenK1, flanked by genes for a helicase and DNA polymerase, respectively. Some similar examples of such a gene cluster have also already been reported for phages with other hosts than E. coli, e.g., Mycobacterium phage Rosebush [55], Streptococcus phage Dp-1 [56], or Pantoea phage vB_PagS_Vid5 [57]. The described gene cluster might be responsible for the modification of DNA to probably provide resistance against different restriction enzymes. As also described for phage 9g [43], phage HdK1 is resistant to some of the tested restriction enzymes (data not shown) which might be a hint that modified bases also exist in the genome of HdK1.

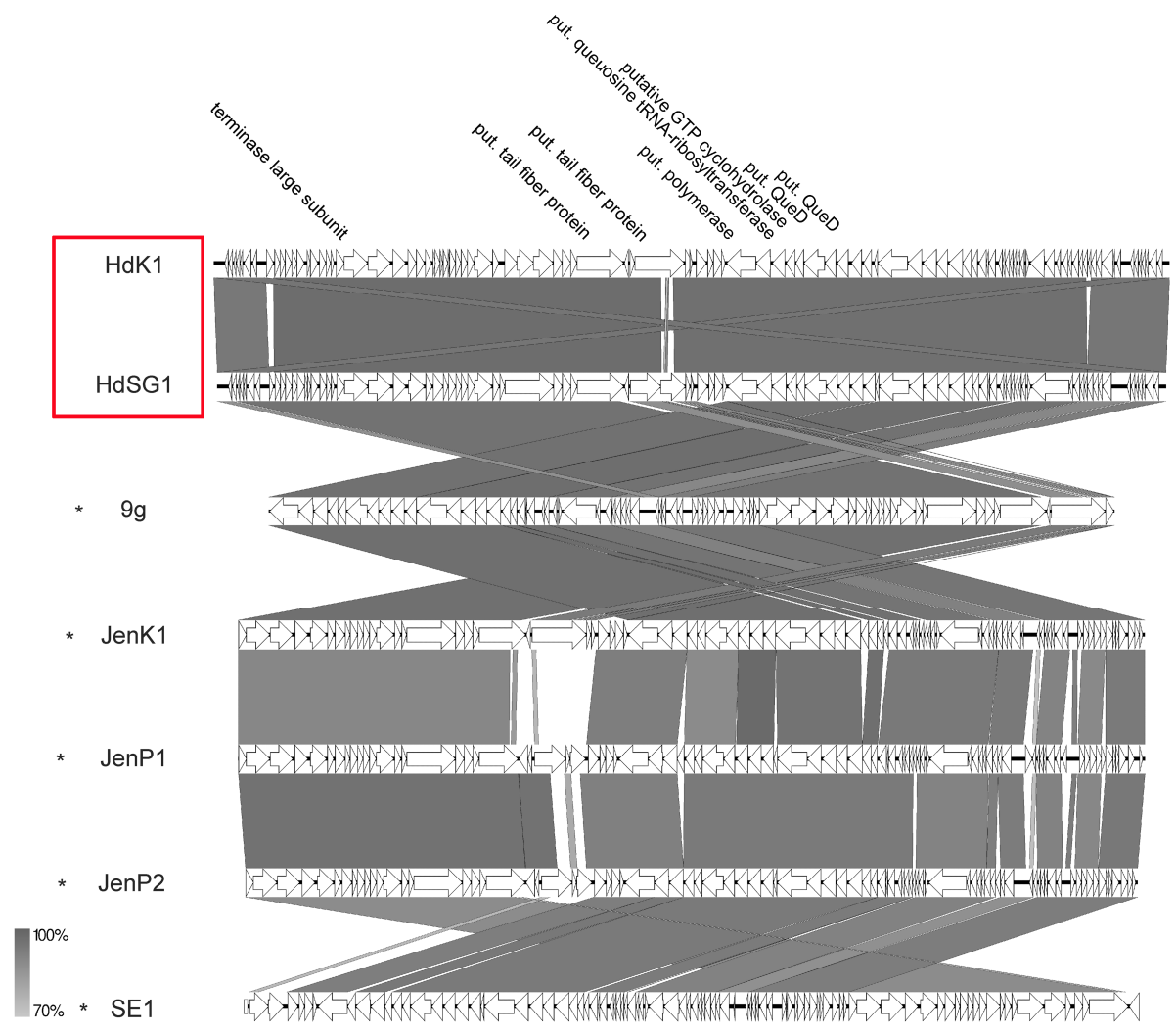

Figure 14. Synteny plot of phages HdK1 and HdSG1 compared to phage $9 \mathrm{~g}$ at the nucleotide level. The figure was generated with EasyFig. Asterisks indicate official classification as members of the ICTV-recognized genus Nonagvirus. Isolates of this study are marked in red. 


\subsubsection{HK578-Like Viruses}

A further group of siphoviruses isolated in this study was clustered into the ICTV-classified genus Dhillonvirus based on their morphological similarities, revealing quite flexible tails and genomic organization. Further members of this group, such as phages slur05 and slur06, phage EP23, or phage JL1, have already been described in the literature [58-60]. They all show nearly the same gene content with small variations (Figure 15). Our phages revealed genome sizes of about $42-47 \mathrm{~kb}$ with a GC content of about $54.4 \%$ and carried no tRNA genes. Interestingly, WFI, WF5505, and PTXU06 differ in particular in one gene (WF5505 gp38) for a tail fiber (Figure 13, marked in blue), which might correlate to the distinct differences of our isolated phages in regard to their host spectrum and might make WF5505 specific for serotype O25:H4.

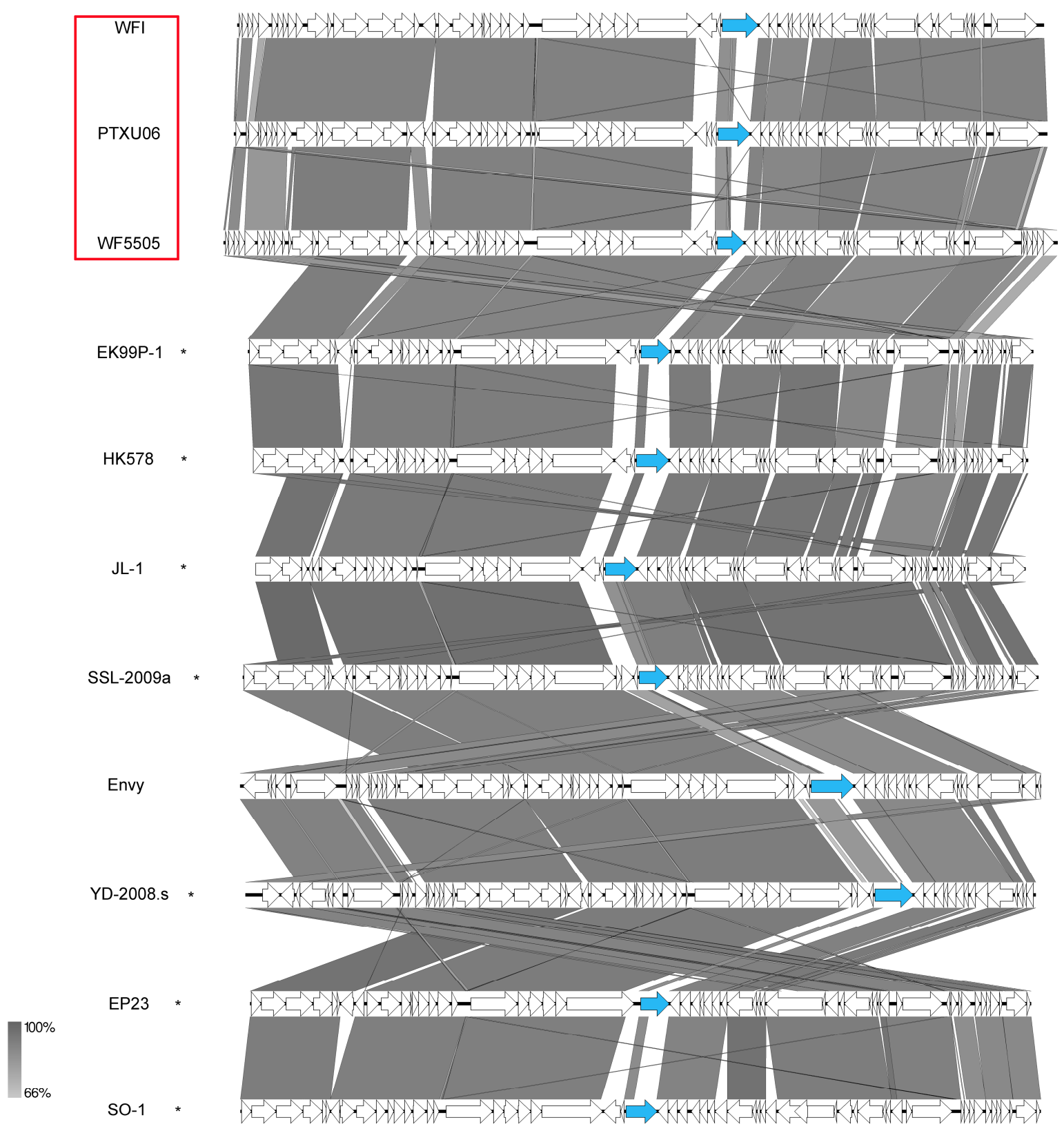

Figure 15. Synteny plot of phages WFIE160, WF5505, and PTXU06 and an overview of the genomic organization of selected HK578-like phages at the nucleotide level. The figure was generated with EasyFig. Asterisks indicate ICTV-classified species within the genus as Dhillonvirus. Isolates of this study are marked in red. 


\subsubsection{Rtp-Like Viruses}

A further siphovirus of our study was classified as a new member of the Tunavirinae subfamily. The first sequence analysis showed that MM01, which was isolated from horse dung, had the same genomic organization as other members of the Tunavirinae subfamily with rtpviruses as its closest relatives (Supplementary Figure S5) [61-64]. The rtpviruses revealed an average genome size of 45.8 $\mathrm{kb}$ with an average GC content of $44.2 \%$ and carried one single tRNA, while the genome size of phage MM01 is a little bit smaller $(43.2 \mathrm{~kb})$. Variations in gene content were observed again in the cluster for tail fiber proteins. Generally, those genes were identified at different locations in the genome. While one gene is usually embedded in the cluster for other structural components, e.g., minor tail proteins or a tail tape measure protein, another gene for a tail fiber component is located on the other strand. Interestingly, phage MM01 might harbor three genes for putative tail fibers, namely MM01_00019, MM01_00036, and MM01_00044, though the real function of MM01_00019 is not clear yet. While MM01_00036 is quite similar to its homolog in phage RTP, Gp44 shows similarities to a tail fiber protein of phage KBNP1711. Electron microscopy revealed that MM01 has a flexible tail of about $153 \mathrm{~nm}$ and a head length of about $64 \mathrm{~nm}$. Similar studies with phage RTP showed that it has a unique tail tip consisting of four leaf-like structures arranged in a rosette [65].

\subsection{7. pSf1-Like Viruses}

Phage G29-2 was isolated from manure in Germany and showed characteristic features of members of the Siphoviridae family. It has a flexible tail with a length of about $143 \mathrm{~nm}$ and an icosahedral head with a length of about $69 \mathrm{~nm}$. Sequence comparison and phylogenomic analysis via VICTOR unveiled that, together with its closest relative Shigella phage pSf-1, G29-2 can be classified into the Tunavirus. pSf-1 was also reported to display a quite flexible tail with a length of $103 \mathrm{~nm}$ and a head diameter of $73 \mathrm{~nm}$ [66]. Both phages revealed a genome size of about $51 \mathrm{~kb}$ with a GC content of $44 \%$, showing no signs of tRNAs.

\subsubsection{T4-Like Viruses}

After analysis of the myoviruses, 27 of our isolates were classified as new members of the Tevenvirinae subfamily, including the three genera, namely Tequatrovirus, Mosigvirus, and Krischvirus. Revealing morphological features undistinguishable from phage T4, only a genomic analysis of those isolates provided further insights into their grade of relatedness (Figure 7). Originally, all those different genera belonged to the T4likevirus, but were separated into different genera by the ICTV based on different features. Phylogenetic analysis of phage RB49 revealed a distance from T4 and justified a classification as a pseudo-T-even phage [67]. Some members of this genus (Krischvirus) have also been described in literature dealing with different topics [68-71]; they have a slightly smaller genome size $(\sim 164 \mathrm{~kb})$ than T4-likes, carry no tRNAs, and their DNA contains cytosine and no 5-hydroxymethylcytosine. In comparison, RB69-like phages are much more closely related to T4 at the nucleotide level than krischviruses; most of the members, such as RB69 or PhaPEC2 [72,73], have a genome size of about $168 \mathrm{~kb}$, similar to T4, and reveal two or three tRNAs while tequatroviruses of our study displayed up to 12 tRNAs. Though our isolated phages belonging to those three genera are quite similar, in fact forming a single genus cluster "E" in the VICTOR analysis (Figure 7), showing only small variations in gene content, and being, therefore, considered as new isolates, but not new species, their lytic behavior on different E. coli strains (Figure 4) showed distinct differences. Interestingly, we identified some variations in particular in gp37- and gp38-likes of T4, encoding putative components of a tail fiber.

Here, we have uncovered many nearly identical tequatroviruses, as evidenced by the sequence similarities of their structural protein genes and electron microscopy images. An interesting aspect of new phage discovery is their host specificity, which is determined to a great extent by their fiber protein structure [74]. Due to horizontal gene transfer, sequence similarity of the tail fibers, especially 
those of the receptor-binding C-termini, often does not show correlation with the rest of the structural proteins. The C-terminal ends of the translated gp37 genes of phages MM02, KAW3E185, WFbE185, G2285, G53, KAW1E185, R5505, and G2469 all have between seven and nine repeats of the putative iron ion coordinating His- $\mathrm{X}$-His sequence motifs at their $\mathrm{C}$-terminal ends. This means that the long tail fiber tips of these phages are likely to have a similar structure to the gp37 needle of T4 (PDB 2XGF; [75]). This is confirmed by HHpred analysis [76].

The C-terminal ends of the translated gp37 genes of phages G10400 and G50 are predicted to be structurally similar to the C-terminal end of gp37 of Salmonella phage S16 (Protein Data Bank (PDB) 6F45, [77]). For phage S16, gp38 stays bound to gp37 and is probably the de facto receptor-binding protein. Indeed, for phages G10400 and G50, the gp38 genes also show predicted structural similarity to gp38 from S16.

The other new gp37 sequences are not predicted to have structural similarity to gp37 of phage T4 or S16. These are interesting candidates for future structural studies. Previously known tequatrovirus gp37 sequences also show predicted structural similarity to gp37 of T4 or S16, or fall in the unknown category. For example, the E. coli phage T2 gp37 is predicted to have structural similarity to the Salmonella phage S16.

\subsubsection{V5-Like Viruses}

One further group of larger myoviruses was classified as Vequintavirus belonging to the subfamily Vequintavirinae. This subfamily consists of four genera Avunavirus (1 sp.; $121 \mathrm{~kb}, 40.0 \% \mathrm{G}+\mathrm{C}, 17$ tRNAs); Certrevirus (5 sp.; 150 kb, 51 mol\% G+C, 17 tRNAs); Seunavirus (4 sp; 148 kb, 46\% G+C, 24 tRNAs); and Vequintavirus ( $8 \mathrm{sp} . ; 138 \mathrm{~kb}, 44 \mathrm{~mol} \% \mathrm{G}+\mathrm{C}, 5 \mathrm{tRNAs}$ ). The type phage for that group, V5, was used in a set of phages for typing of Shiga-toxin-producing E. coli O157:H7. At least further seven vequintaviruses have been described in the literature before [58,78-83]; most of them had E. coli O157:H7 as their host. Two of our isolated phages, EdH4 and HdK5, revealed characteristic features of this group and, thus, were included in that genus (Supplementary Figure S6). Both have short terminal redundancies of $458 \mathrm{bp}$, a genome size of 136,031 bp and 139,328 bp, respectively, and carry seven tRNAs.

\subsubsection{PBECO4-Like Viruses}

Apart from already described phages of this study with "regular" well-known genome sizes, such as, for instance, for tequatroviruses, we also isolated a phage, G17, which revealed a genome size of more than $370 \mathrm{~kb}$. Such phages with genome sizes $>200 \mathrm{~kb}$ are classified as "jumbo phages". Due to the rising number of genome sequences, more and more of those have been recently identified to originate from various habitats and infect different host genera [84]. The most famous and revealing the largest genome so far is Bacillus megaterium phage G [85]. Further well-known jumbo phages infecting other genera are, for instance, Klebsiella phage vB_KleM-Rak2 [86], Cronobacter phage GAP32 [87], and Pseudomonas phage $\phi K Z$ [88]. Analysis of the genome of phage G17 revealed 659 CDS and seven tRNAs; sequence coverage showed large terminal redundancies of about $20 \mathrm{~kb}$. Comparison with the GenBank database for tailed phages (taxid:28883) showed high similarities (VICTOR similarities >89) to phages 121Q, slurp01 [89], and PBECO4, underlined by similarities in gene content and genome organization (Supplementary Figure S7). Apart from its large genome, its morphology displayed large features with a head length of about $139 \mathrm{~nm}$ and a head width of about $129 \mathrm{~nm}$ (Table 1). Recently, the ICTV proposed to create a new genus, Asteriusvirus, derived from Greek mythology for those gigantic E. coli phages related to PBECO4 isolated in Korea [90]. Thus, G17 is considered to be a member of this new genus.

\subsection{Proposal of Newly Created Genera}

During our analysis, we recognized some phages that, according to their sequence similarity, were considered either as completely novel, e.g., PTXU04, or as a new member of a yet to be classified genus. 


\subsubsection{7-KN2-1-Like Viruses}

Myovirus KWBSE43-6 was isolated from sewage in Braunschweig, Germany, and revealed a highly specific behavior in our host range analysis, lysing only one specific E. coli strain of our set. BLASTn analysis revealed that its nucleotide sequence was similar to five other unclassified phages, mainly Klebsiella phages, with VICTOR similarity values between 80 and $85 \%$, forming a single VICTOR genus cluster (Figure 7). Only two phages of this new genus have been published so far. Besides Serratia phage vB_Sru-IME250 [91], only the first isolate of this group, Klebsiella phage 0507-KN2-1, was further analyzed in particular in regard to its polysaccharide depolymerase [92]. All of the included phages revealed genome sizes between 154 and $160 \mathrm{~kb}$, an average GC content of about 46.8\%, and four to seven tRNAs. Based on a synteny plot (Supplementary Figure S8) of all those phages, the main variations were again identified in the putative cluster for adsorption and receptor binding. Gp148 of KWBSE43-6 displayed a conserved domain for a putative polygalacturonase (Pgu1 COG5434). Deduced amino acid sequences of following genes downstream were partially similar to annotated tailspike proteins though did not reveal any conserved domains. As KWBSE43-6 lysed only one E. coli strain and showed distinct similarities to Klebsiella phages at the sequence level, we also tested this phage on four Klebsiella oxytoca and 15 Klebsiella pneumoniae strains (Table S2). However, no successful lysis by emerging plaques was detected on those strains. Based on the analyzed sequence similarities, we intend to create a new genus "Taipeivirus" originating from the first isolate, phage 0507-KN2-1, which was isolated from sewage in Taipei.

\subsubsection{ECML-117-Like Viruses}

During genome analysis of phages WFC and WFH, we determined strong similarities to only two other phage genomes in GenBank at the nucleotide level, namely phage ECML-117 and FEC19 (VICTOR similarity values $>90 \%$, forming a single genus cluster) (Supplementary Figure S9). Sequencing of WFC and WFH resulted in contigs with a final size of 72,472 and 71,283 bp, respectively, including a terminal repeat of about $3.7 \mathrm{~kb}$ each. None of the analyzed phages revealed tRNAs in their genome. Based on phage WFC, we intend to create a new genus "Wifcevirus".

\subsection{3. phAPEC8-Like Viruses}

According to the VICTOR analysis (Figure 7), phage Schickermooser was identified as a new strain of phage ESCO13, which was isolated in France in 2014. Together with phages ESCO5, ZCKP1, and phAPEC8, they form a maximally supported and yet unclassified cluster in the phylogenomic analysis of the Myoviridae family (Figure 7). All of them display genome sizes between 147 and $151 \mathrm{~kb}$ with an average GC content of 39\%. For phage Schickermooser, we also identified a terminal repeat of $328 \mathrm{bp}$. Additionally, 10-13 tRNAs and a conserved genome structure (Supplementary Figure S10) were detected in all members of that group. Apart from phage Schickermooser, some morphological features were also described in the literature for phage ZCKP1 [93]. Electron microscopy revealed that ZCKP1 had typical characteristics of a myovirus with an icosahedral head and a contractile tail. It has a head size of about $80 \mathrm{~nm}$ and a tail length of about $138 \mathrm{~nm}$, while the tail of phage Schickermooser is shorter. In contrast to the phages of our study, ZCKP1 was isolated on a Klebsiella pneumoniae strain in Egypt. Host range analysis of that phage revealed that it was capable of infecting and lysing various strains of different members of the Enterobacteriaceae-like K. pneumoniae, Proteus mirabilis, and E. coli. Based on phage phAPEC8, which was described as the first member of this new genus [94], we intend to call this new genus "Phapecoctavirus".

\section{Conclusions}

Classification and taxonomy of bacterial viruses is the responsibility of the International Committee in the Taxonomy of Viruses (ICTV). This classification was mainly based on morphological studies $[95,96]$ and properties of the hereditary material until the current era of sequencing, and its new nucleotide 
sequencing technologies have led to vast numbers of new, yet unclassified, phage genomes being entered into public databases every year [17]. Deeper genomic analyses of some of these data have led to the creation of a fourth family in the order Caudovirales, including different genera of myoviruses, and hence revealing the limitations of a solely morphology-based classification and calling for more accurate methods (e.g., sequence-based approaches). Based on the now available data, different approaches and tools for genome- and proteome-based taxonomy have been developed [36,97-99] and discussed by the ICTV. Currently, there are 410 ratified genera and 28 families. However, due to the still rapidly rising number of available phage genomes, many phage genomes still remain unclassified. To that end, VICTOR [36], a modern phylogeny-driven classification, was recently developed and yields phylogenies with high agreement with the ICTV classification, including the majority of taxa being well-supported and monophyletic. This approach is fast and was even applied to a large dataset of more than 4000 unclassified phage sequences from GenBank [36]. In our study, VICTOR supported the proposal of seven new genera, thus improving the taxonomy of E. coli phages, in particular. Apart from the taxonomic point of view, this study also shows that though having been already intensively studied for decades, novel phages against $E$. coli can still be isolated that show no similarities to known Escherichia phages in databases at the nucleotide level at all. These so far unknown sequences offer new possibilities for different aspects of phage research apart from taxonomy. Analysis of their genomes might give insight into different mechanisms of phage-host interaction and replication as the overall genome composition and organization might vary from those that are already known. In regard to future applications of phages or phage components, completely novel phage genomes might also act as sources for identification of new mechanisms for host takeover or enzymes that might help to fight antimicrobial resistance in the future. Our analysis of tail fibers showed that, though we isolated phages that revealed a very high similarity at the nucleotide level, only small genomic changes might vary the host spectrum. Thus, it is still worth looking for new phages to obtain more insight into the diverse phage biology and to enlarge the number of alternatives to fight antimicrobial resistance (AMR) infections.

Supplementary Materials: The following are available online at http://www.mdpi.com/1999-4915/11/5/454/s1, Table S1: E. coli strains for phage isolation, characterization, and propagation, Table S2: Klebsiella strains and growth conditions used for host spectrum analyses of phages KWBSE43-6 and Goslar, Table S3: Additional information on phages isolated in this study, Table S4: Morphological and genomic features of isolated phages of this study, Table S5: Pairwise VICTOR intergenomic sitance and similarity data on isolated phages, Table S6: Mascot research results for peptide fingerprinting analysis of structural proteins of phages PTXU04 and Goslar, Figure S1: Dot plot analysis of genomes of isolated podoviruses of this study compared to related genomes and further members of different genera of the Podoviridae family, Figure S2: Dot plot analysis of genomes of isolated siphoviruses of this study compared to related genomes and further members of different genera of the Siphoviridae family, Figure S3: Dot plot analysis of genomes of isolated myoviruses of this study compared to related genomes and further members of different genera of the Myoviridae family, Figure S4: Time-limited digestion of genomic DNA of phage PTXU04 with BAL 31, followed by complete hydrolysis with BgII, Figure S5: Synteny plot of phage MM01 compared to related phages of the rtpviruses and phage T1 at the nucleotide level, Figure S6: Genomic organization of phages EdH4 and Hdk5 compared to related viruses at the nucleotide level, Figure S7: Synteny plot of phage G17 compared to related asteriusviruses at the nucleotide level, Figure S8: Genome organization of phage KWBSE43-6 compared to related phages at the nucleotide level, Figure S9: Synteny plot of phage WFC and WFH compared to related phages at the nucleotide level, Figure S10: Synteny plot of phage Schickermooser compared to related phages at the nucleotide level.

Author Contributions: J.W. and I.H.E.K. conceived the study idea, I.H.E.K. isolated phages and analyzed phage host ranges, J.W. and J.P.M.K. performed bioinformatic analyses, M.N. analyzed peptide fingerprinting results, M.R. performed TEM analysis, M.J.v.R. analyzed tail fiber genes, A.M.K., E.M.A. and J.W. performed taxonomic classification, J.W., M.J.v.R., and I.K. wrote the manuscript. All authors revised and approved the manuscript.

Funding: E.M.A. gratefully acknowledges the support of the Biotechnology and Biological Sciences Research Council Institute Strategic Programme Gut Microbes and Health (BB/R012490/1) and its constituent project BBS/E/F/000PR10353. I.H.E.K. was supported by the German Federal Environmental Foundation (DBU, AZ 32726/01). J.P.M. was supported by Deutsche Forschungsgemeinschaft within "Sonderforschungsbereich TRR 51". M.J.v.R. is funded by grant BFU2017-82207-P from the Spanish Ministry of Science, Innovation and Universities, State Agency of Research, co-financed by the European Regional Development Fund of the European Union.

Acknowledgments: We gratefully thank Antje Flieger and Angelika Fruth (RKI, Wernigerode, Germany) for their assistance with serotyping of E. coli strains, Marcus Fulde (FU Berlin) for providing some APEC strains, Phage 
Technology Center GmbH (Bönen) for ESBL positive strains isolated from poultry, Ina Schleicher for her help with electron microscopy, Stephanie Peter for technical assistance, and all students of the DSMZ Phage Trapper Project who in any way contributed to the E. coli phage diversity.

Conflicts of Interest: The authors declare no conflict of interest.

\section{References}

1. Meier-Kolthoff, J.P.; Hahnke, R.L.; Petersen, J.; Scheuner, C.; Michael, V.; Fiebig, A.; Rohde, C.; Rohde, M.; Fartmann, B.; Goodwin, L.A.; et al. Complete genome sequence of DSM 30083(T), the type strain (U5/41(T)) of Escherichia coli, and a proposal for delineating subspecies in microbial taxonomy. Stand. Genom. Sci. 2014, 9, 2. [CrossRef]

2. Cabal, A.; Garcia-Castillo, M.; Canton, R.; Gortazar, C.; Dominguez, L.; Alvarez, J. Prevalence of Escherichia coli Virulence Genes in Patients with Diarrhea and a Subpopulation of Healthy Volunteers in Madrid, Spain. Front. Microbiol. 2016, 7, 641. [CrossRef]

3. Kaper, J.B.; Nataro, J.P.; Mobley, H.L. Pathogenic Escherichia coli. Nat. Rev. Microbiol. 2004, 2, $123-140$. [CrossRef]

4. Croxen, M.A.; Law, R.J.; Scholz, R.; Keeney, K.M.; Wlodarska, M.; Finlay, B.B. Recent advances in understanding enteric pathogenic Escherichia coli. Clin. Microbiol. Rev. 2013, 26, 822-880. [CrossRef] [PubMed]

5. Clements, A.; Young, J.C.; Constantinou, N.; Frankel, G. Infection strategies of enteric pathogenic Escherichia coli. Gut Microbes. 2012, 3, 71-87. [CrossRef] [PubMed]

6. Ghosh, C.; Sarkar, P.; Issa, R.; Haldar, J. Alternatives to Conventional Antibiotics in the Era of Antimicrobial Resistance. Trends Microbiol. 2019. [CrossRef]

7. Dufour, N.; Debarbieux, L.; Fromentin, M.; Ricard, J.D. Treatment of Highly Virulent Extraintestinal Pathogenic Escherichia coli Pneumonia with Bacteriophages. Crit. Care Med. 2015, 43, e190-e198. [CrossRef]

8. Oliveira, A.; Sereno, R.; Azeredo, J. In vivo efficiency evaluation of a phage cocktail in controlling severe colibacillosis in confined conditions and experimental poultry houses. Vet. Microbiol. 2010, 146, 303-308. [CrossRef] [PubMed]

9. Cobian Guemes, A.G.; Youle, M.; Cantu, V.A.; Felts, B.; Nulton, J.; Rohwer, F. Viruses as Winners in the Game of Life. Annu. Rev. Virol. 2016, 3, 197-214. [CrossRef]

10. Suttle, C.A. Marine viruses-major players in the global ecosystem. Nat. Rev. Microbiol. 2007, 5, 801-812. [CrossRef] [PubMed]

11. Brussaard, C.P.; Wilhelm, S.W.; Thingstad, F.; Weinbauer, M.G.; Bratbak, G.; Heldal, M.; Kimmance, S.A.; Middelboe, M.; Nagasaki, K.; Paul, J.H.; et al. Global-scale processes with a nanoscale drive: The role of marine viruses. Isme. J. 2008, 2, 575-578. [CrossRef] [PubMed]

12. Breitbart, M.; Bonnain, C.; Malki, K.; Sawaya, N.A. Phage puppet masters of the marine microbial realm. Nat. Microbiol. 2018, 3, 754-766. [CrossRef]

13. Keen, E.C. A century of phage research: Bacteriophages and the shaping of modern biology. Bioessays 2015, 37, 6-9. [CrossRef] [PubMed]

14. Kropinski, A.M. Bacteriophage research-What we have learnt and what still needs to be addressed. Res. Microbiol. 2018, 169, 481-487. [CrossRef] [PubMed]

15. Adriaenssens, E.M.; Wittmann, J.; Kuhn, J.H.; Turner, D.; Sullivan, M.B.; Dutilh, B.E.; Jang, H.B.; van Zyl, L.J.; Klumpp, J.; Lobocka, M.; et al. Taxonomy of prokaryotic viruses: 2017 update from the ICTV Bacterial and Archaeal Viruses Subcommittee. Arch. Virol. 2018, 163, 1125-1129. [CrossRef] [PubMed]

16. Grose, J.H.; Casjens, S.R. Understanding the enormous diversity of bacteriophages: The tailed phages that infect the bacterial family Enterobacteriaceae. Virology 2014, 468-470, 421-443. [CrossRef]

17. Adriaenssens, E.; Brister, J.R. How to Name and Classify Your Phage: An Informal Guide. Viruses 2017, 9, 70. [CrossRef] [PubMed]

18. Roux, S.; Adriaenssens, E.M.; Dutilh, B.E.; Koonin, E.V.; Kropinski, A.M.; Krupovic, M.; Kuhn, J.H.; Lavigne, R.; Brister, J.R.; Varsani, A.; et al. Minimum Information about an Uncultivated Virus Genome (MIUViG). Nat. Biotechnol. 2018. [CrossRef] [PubMed]

19. Michniewski, S.; Redgwell, T.; Grigonyte, A.; Rihtman, B.; Aguilo-Ferretjans, M.; Christie-Oleza, J.; Jameson, E.; Scanlan, D.J.; Millard, A.D. Riding the wave of genomics to investigate aquatic coliphage diversity and activity. Environ. Microbiol. 2019. [CrossRef] 
20. Svab, D.; Falgenhauer, L.; Rohde, M.; Szabo, J.; Chakraborty, T.; Toth, I. Identification and Characterization of T5-Like Bacteriophages Representing Two Novel Subgroups from Food Products. Front. Microbiol. 2018, 9 , 202. [CrossRef]

21. Korf, I.H.E.; Bierbrodt, A.; Mengden, R.; Kittler, S.; Rohde, C.; Rohde, M.; Lehnherr, T.; Fruth, A.; Flieger, A.; Lehnherr, H.; et al. In vitro evaluation of a phage cocktail to prevent infections with Escherichia coli. Viruses 2019, under revision.

22. Braun, S.D.; Ahmed, M.F.; El-Adawy, H.; Hotzel, H.; Engelmann, I.; Weiss, D.; Monecke, S.; Ehricht, R. Surveillance of Extended-Spectrum Beta-Lactamase-Producing Escherichia coli in Dairy Cattle Farms in the Nile Delta, Egypt. Front. Microbiol. 2016, 7, 1020. [CrossRef]

23. Beilstein, F.; Dreiseikelmann, B. Bacteriophages of freshwater Brevundimonas vesicularis isolates. Res. Microbiol. 2006, 157, 213-219. [CrossRef]

24. Dreiseikelmann, B.; Bunk, B.; Sproer, C.; Rohde, M.; Nimtz, M.; Wittmann, J. Characterization and genome comparisons of three Achromobacter phages of the family Siphoviridae. Arch. Virol. 2017, 162, 2191-2201. [CrossRef] [PubMed]

25. Ackermann, H.W. Frequency of morphological phage descriptions in the year 2000. Brief review. Arch. Virol. 2001, 146, 843-857. [CrossRef]

26. Baym, M.; Kryazhimskiy, S.; Lieberman, T.D.; Chung, H.; Desai, M.M.; Kishony, R. Inexpensive multiplexed library preparation for megabase-sized genomes. PLoS ONE 2015, 10, e0128036. [CrossRef] [PubMed]

27. Loessner, M.J.; Inman, R.B.; Lauer, P.; Calendar, R. Complete nucleotide sequence, molecular analysis and genome structure of bacteriophage A118 of Listeria monocytogenes: Implications for phage evolution. Mol. Microbiol. 2000, 35, 324-340. [CrossRef]

28. Wittmann, J.; Dreiseikelmann, B.; Rohde, M.; Meier-Kolthoff, J.P.; Bunk, B.; Rohde, C. First genome sequences of Achromobacter phages reveal new members of the N4 family. Virol. J. 2014, 11, 14. [CrossRef]

29. Bankevich, A.; Nurk, S.; Antipov, D.; Gurevich, A.A.; Dvorkin, M.; Kulikov, A.S.; Lesin, V.M.; Nikolenko, S.I.; Pham, S.; Prjibelski, A.D.; et al. SPAdes: A new genome assembly algorithm and its applications to single-cell sequencing. J. Comput. Biol. 2012, 19, 455-477. [CrossRef] [PubMed]

30. Thorvaldsdottir, H.; Robinson, J.T.; Mesirov, J.P. Integrative Genomics Viewer (IGV): High-performance genomics data visualization and exploration. Brief. Bioinform. 2013, 14, 178-192. [CrossRef]

31. Seemann, T. Prokka: Rapid prokaryotic genome annotation. Bioinformatics 2014, 30, 2068-2069. [CrossRef]

32. Grazziotin, A.L.; Koonin, E.V.; Kristensen, D.M. Prokaryotic Virus Orthologous Groups (pVOGs): A resource for comparative genomics and protein family annotation. Nucleic Acids Res. 2017, 45, D491-D498. [CrossRef]

33. Carver, T.; Harris, S.R.; Berriman, M.; Parkhill, J.; McQuillan, J.A. Artemis: An integrated platform for visualization and analysis of high-throughput sequence-based experimental data. Bioinformatics 2012, 28, 464-469. [CrossRef] [PubMed]

34. Naville, M.; Ghuillot-Gaudeffroy, A.; Marchais, A.; Gautheret, D. ARNold: A web tool for the prediction of Rho-independent transcription terminators. RNA Biol. 2011, 8, 11-13. [CrossRef] [PubMed]

35. Lowe, T.M.; Eddy, S.R. tRNAscan-SE: A program for improved detection of transfer RNA genes in genomic sequence. Nucleic Acids Res. 1997, 25, 955-964. [CrossRef]

36. Meier-Kolthoff, J.P.; Goker, M. VICTOR: Genome-based phylogeny and classification of prokaryotic viruses. Bioinformatics 2017, 33, 3396-3404. [CrossRef] [PubMed]

37. Bischoff, V.; Bunk, B.; Meier-Kolthoff, J.P.; Sproer, C.; Poehlein, A.; Dogs, M.; Nguyen, M.; Petersen, J.; Daniel, R.; Overmann, J.; et al. Cobaviruses-A new globally distributed phage group infecting Rhodobacteraceae in marine ecosystems. Isme J. 2019. [CrossRef]

38. Meier-Kolthoff, J.P.; Auch, A.F.; Klenk, H.P.; Goker, M. Genome sequence-based species delimitation with confidence intervals and improved distance functions. BMC Bioinform. 2013, 14, 60. [CrossRef] [PubMed]

39. Letunic, I.; Bork, P. Interactive tree of life (iTOL) v3: An online tool for the display and annotation of phylogenetic and other trees. Nucleic Acids Res. 2016, 44, W242-W245. [CrossRef] [PubMed]

40. Khan Mirzaei, M.; Eriksson, H.; Kasuga, K.; Haggard-Ljungquist, E.; Nilsson, A.S. Genomic, proteomic, morphological, and phylogenetic analyses of vB_EcoP_SU10, a podoviridae phage with C3 morphology. PLOS ONE 2014, 9, e116294.

41. Savalia, D.; Westblade, L.F.; Goel, M.; Florens, L.; Kemp, P.; Akulenko, N.; Pavlova, O.; Padovan, J.C.; Chait, B.T.; Washburn, M.P.; et al. Genomic and proteomic analysis of phiEco32, a novel Escherichia coli bacteriophage. J. Mol. Biol. 2008, 377, 774-789. [CrossRef] 
42. Krumsiek, J.; Arnold, R.; Rattei, T. Gepard: A rapid and sensitive tool for creating dotplots on genome scale. Bioinformatics 2007, 23, 1026-1028. [CrossRef]

43. Kulikov, E.E.; Golomidova, A.K.; Letarova, M.A.; Kostryukova, E.S.; Zelenin, A.S.; Prokhorov, N.S.; Letarov, A.V. Genomic sequencing and biological characteristics of a novel Escherichia coli bacteriophage 9g, a putative representative of a new Siphoviridae genus. Viruses 2014, 6, 5077-5092. [CrossRef] [PubMed]

44. Mahadevan, P.; King, J.F.; Seto, D. CGUG: In silico proteome and genome parsing tool for the determination of "core" and unique genes in the analysis of genomes up to ca. 1.9 Mb. BMC Res. Notes 2009, 2, 168. [CrossRef]

45. Mahadevan, P.; King, J.F.; Seto, D. Data mining pathogen genomes using GeneOrder and CoreGenes and CGUG: Gene order, synteny and in silico proteomes. Int. J. Comput. Biol. Drug Des. 2009, 2, 100-114. [CrossRef] [PubMed]

46. Li, Y.; Chen, M.; Tang, F.; Yao, H.; Lu, C.; Zhang, W. Complete genome sequence of the novel lytic avian pathogenic coliphage NJ01. J. Virol. 2012, 86, 13874-13875. [CrossRef] [PubMed]

47. Nho, S.W.; Ha, M.A.; Kim, K.S.; Kim, T.H.; Jang, H.B.; Cha, I.S.; Park, S.B.; Kim, Y.K.; Jung, T.S. Complete genome sequence of the bacteriophages ECBP1 and ECBP2 isolated from two different Escherichia coli strains. J. Virol. 2012, 86, 12439-12440. [CrossRef]

48. Sullivan, M.J.; Petty, N.K.; Beatson, S.A. Easyfig: A genome comparison visualizer. Bioinformatics 2011, 27, 1009-1010. [CrossRef] [PubMed]

49. Dobbins, A.T.; George, M., Jr.; Basham, D.A.; Ford, M.E.; Houtz, J.M.; Pedulla, M.L.; Lawrence, J.G.; Hatfull, G.F.; Hendrix, R.W. Complete genomic sequence of the virulent Salmonella bacteriophage SP6. J. Bacteriol. 2004, 186, 1933-1944. [CrossRef] [PubMed]

50. Stummeyer, K.; Schwarzer, D.; Claus, H.; Vogel, U.; Gerardy-Schahn, R.; Muhlenhoff, M. Evolution of bacteriophages infecting encapsulated bacteria: Lessons from Escherichia coli K1-specific phages. Mol. Microbiol. 2006, 60, 1123-1135. [CrossRef] [PubMed]

51. Baig, A.; Colom, J.; Barrow, P.; Schouler, C.; Moodley, A.; Lavigne, R.; Atterbury, R. Biology and Genomics of an Historic Therapeutic Escherichia coli Bacteriophage Collection. Front. Microbiol. 2017, 8, 1652. [CrossRef] [PubMed]

52. Carstens, A.B.; Kot, W.; Hansen, L.H. Complete Genome Sequences of Four Novel Escherichia coli Bacteriophages Belonging to New Phage Groups. Genome Announc. 2015, 3. [CrossRef]

53. Thiaville, J.J.; Kellner, S.M.; Yuan, Y.; Hutinet, G.; Thiaville, P.C.; Jumpathong, W.; Mohapatra, S.; Brochier-Armanet, C.; Letarov, A.V.; Hillebrand, R.; et al. Novel genomic island modifies DNA with 7-deazaguanine derivatives. Proc. Natl. Acad. Sci. USA 2016, 113, E1452-E1459. [CrossRef]

54. Sazinas, P.; Redgwell, T.; Rihtman, B.; Grigonyte, A.; Michniewski, S.; Scanlan, D.J.; Hobman, J.; Millard, A. Comparative Genomics of Bacteriophage of the Genus Seuratvirus. Genome Biol. Evol. 2018, 10, 72-76. [CrossRef] [PubMed]

55. Pedulla, M.L.; Ford, M.E.; Houtz, J.M.; Karthikeyan, T.; Wadsworth, C.; Lewis, J.A.; Jacobs-Sera, D.; Falbo, J.; Gross, J.; Pannunzio, N.R.; et al. Origins of highly mosaic mycobacteriophage genomes. Cell 2003, 113, 171-182. [CrossRef]

56. Sabri, M.; Hauser, R.; Ouellette, M.; Liu, J.; Dehbi, M.; Moeck, G.; Garcia, E.; Titz, B.; Uetz, P.; Moineau, S. Genome annotation and intraviral interactome for the Streptococcus pneumoniae virulent phage Dp-1. J. Bacteriol. 2011, 193, 551-562. [CrossRef]

57. Simoliunas, E.; Simoliuniene, M.; Kaliniene, L.; Zajanckauskaite, A.; Skapas, M.; Meskys, R.; Kaupinis, A.; Valius, M.; Truncaite, L. Pantoea Bacteriophage vB_PagS_Vid5: A Low-Temperature Siphovirus That Harbors a Cluster of Genes Involved in the Biosynthesis of Archaeosine. Viruses 2018, 10, 583. [CrossRef]

58. Smith, R.; O’Hara, M.; Hobman, J.L.; Millard, A.D. Draft Genome Sequences of 14 Escherichia coli Phages Isolated from Cattle Slurry. Genome Announc. 2015, 3. [CrossRef]

59. Chang, H.W.; Kim, K.H. Comparative genomic analysis of bacteriophage EP23 infecting Shigella sonnei and Escherichia coli. J. Microbiol. 2011, 49, 927-934. [CrossRef]

60. Pan, F.; Wu, H.; Liu, J.; Ai, Y.; Meng, X.; Meng, R.; Meng, Q. Complete genome sequence of Escherichia coli O157:H7 lytic phage JL1. Arch. Virol. 2013, 158, 2429-2432. [CrossRef]

61. Halter, M.C.; Zahn, J.A. Characterization of a novel lytic bacteriophage from an industrial Escherichia coli fermentation process and elimination of virulence using a heterologous CRISPR-Cas9 system. J. Ind. Microbiol. Biotechnol. 2018, 45, 153-163. [CrossRef] 
62. Niu, Y.D.; McAllister, T.A.; Nash, J.H.; Kropinski, A.M.; Stanford, K. Four Escherichia coli O157:H7 phages: A new bacteriophage genus and taxonomic classification of T1-like phages. PLoS ONE 2014, 9, e100426. [CrossRef] [PubMed]

63. Chibeu, A.; Lingohr, E.J.; Masson, L.; Manges, A.; Harel, J.; Ackermann, H.W.; Kropinski, A.M.; Boerlin, P. Bacteriophages with the ability to degrade uropathogenic Escherichia coli biofilms. Viruses 2012, 4, 471-487. [CrossRef] [PubMed]

64. Oliveira, A.; Sousa, J.C.; Silva, A.C.; Melo, L.D.R.; Sillankorva, S. Chestnut Honey and Bacteriophage Application to Control Pseudomonas aeruginosa and Escherichia coli Biofilms: Evaluation in an ex vivo Wound Model. Front. Microbiol. 2018, 9, 1725. [CrossRef]

65. Wietzorrek, A.; Schwarz, H.; Herrmann, C.; Braun, V. The genome of the novel phage Rtp, with a rosette-like tail tip, is homologous to the genome of phage T1. J. Bacteriol. 2006, 188, 1419-1436. [CrossRef]

66. Jun, J.W.; Kim, J.H.; Shin, S.P.; Han, J.E.; Chai, J.Y.; Park, S.C. Characterization and complete genome sequence of the Shigella bacteriophage pSf-1. Res. Microbiol. 2013, 164, 979-986. [CrossRef]

67. Desplats, C.; Dez, C.; Tetart, F.; Eleaume, H.; Krisch, H.M. Snapshot of the genome of the pseudo-T-even bacteriophage RB49. J. Bacteriol. 2002, 184, 2789-2804. [CrossRef]

68. Aleshkin, A.V.; Rubalskii, E.O.; Volozhantsev, N.V.; Verevkin, V.V.; Svetoch, E.A.; Kiseleva, I.A.; Bochkareva, S.S.; Borisova, O.Y.; Popova, A.V.; Bogun, A.G.; et al. A small-scale experiment of using phage-based probiotic dietary supplement for prevention of E. coli traveler's diarrhea. Bacteriophage 2015, 5, e1074329. [CrossRef] [PubMed]

69. Monod, C.; Repoila, F.; Kutateladze, M.; Tetart, F.; Krisch, H.M. The genome of the pseudo T-even bacteriophages, a diverse group that resembles T4. J. Mol. Biol. 1997, 267, 237-249. [CrossRef]

70. Denou, E.; Bruttin, A.; Barretto, C.; Ngom-Bru, C.; Brussow, H.; Zuber, S. T4 phages against Escherichia coli diarrhea: Potential and problems. Virology 2009, 388, 21-30. [CrossRef] [PubMed]

71. Arbiol, C.; Comeau, A.M.; Kutateladze, M.; Adamia, R.; Krisch, H.M. Mobile regulatory cassettes mediate modular shuffling in T4-type phage genomes. Genome. Biol. Evol. 2010, 2, 140-152. [CrossRef]

72. Yeh, L.S.; Hsu, T.; Karam, J.D. Divergence of a DNA replication gene cluster in the T4-related bacteriophage RB69. J. Bacteriol. 1998, 180, 2005-2013.

73. Tsonos, J.; Oosterik, L.H.; Tuntufye, H.N.; Klumpp, J.; Butaye, P.; De Greve, H.; Hernalsteens, J.P.; Lavigne, R.; Goddeeris, B.M. A cocktail of in vitro efficient phages is not a guarantee for in vivo therapeutic results against avian colibacillosis. Vet. Microbiol. 2014, 171, 470-479. [CrossRef] [PubMed]

74. Nobrega, F.L.; Vlot, M.; de Jonge, P.A.; Dreesens, L.L.; Beaumont, H.J.E.; Lavigne, R.; Dutilh, B.E.; Brouns, S.J.J. Targeting mechanisms of tailed bacteriophages. Nat. Rev. Microbiol. 2018, 16, 760-773. [CrossRef]

75. Bartual, S.G.; Otero, J.M.; Garcia-Doval, C.; Llamas-Saiz, A.L.; Kahn, R.; Fox, G.C.; van Raaij, M.J. Structure of the bacteriophage T4 long tail fiber receptor-binding tip. Proc. Natl. Acad. Sci. USA 2010, 107, 20287-20292. [CrossRef]

76. Zimmermann, L.; Stephens, A.; Nam, S.Z.; Rau, D.; Kubler, J.; Lozajic, M.; Gabler, F.; Soding, J.; Lupas, A.N.; Alva, V. A Completely Reimplemented MPI Bioinformatics Toolkit with a New HHpred Server at its Core. J. Mol. Biol. 2018, 430, 2237-2243. [CrossRef]

77. Dunne, M.; Denyes, J.M.; Arndt, H.; Loessner, M.J.; Leiman, P.G.; Klumpp, J. Salmonella Phage S16 Tail Fiber Adhesin Features a Rare Polyglycine Rich Domain for Host Recognition. Structure 2018, 26, 1573-1582.e1574. [CrossRef]

78. Cowley, L.A.; Beckett, S.J.; Chase-Topping, M.; Perry, N.; Dallman, T.J.; Gally, D.L.; Jenkins, C. Analysis of whole genome sequencing for the Escherichia coli O157:H7 typing phages. BMC Genom. 2015, 16, 271. [CrossRef]

79. Kropinski, A.M.; Waddell, T.; Meng, J.; Franklin, K.; Ackermann, H.W.; Ahmed, R.; Mazzocco, A.; Yates, J., 3rd; Lingohr, E.J.; Johnson, R.P. The host-range, genomics and proteomics of Escherichia coli O157:H7 bacteriophage rV5. Virol. J. 2013, 10, 76. [CrossRef] [PubMed]

80. Wilder, J.N.; Lancaster, J.C.; Cahill, J.L.; Rasche, E.S.; Kuty Everett, G.F. Complete Genome Sequence of Enterotoxigenic Escherichia coli Myophage Murica. Genome Announc. 2015, 3. [CrossRef] [PubMed]

81. Dalmasso, M.; Strain, R.; Neve, H.; Franz, C.M.; Cousin, F.J.; Ross, R.P.; Hill, C. Three New Escherichia coli Phages from the Human Gut Show Promising Potential for Phage Therapy. PLoS ONE 2016, 11, e0156773. [CrossRef] [PubMed] 
82. Hong, Y.; Pan, Y.; Harman, N.J.; Ebner, P.D. Complete Genome Sequences of Two Escherichia coli O157:H7 Phages Effective in Limiting Contamination of Food Products. Genome Announc. 2014, 2. [CrossRef]

83. Truncaite, L.; Simoliunas, E.; Zajanckauskaite, A.; Kaliniene, L.; Mankeviciute, R.; Staniulis, J.; Klausa, V.; Meskys, R. Bacteriophage vB_EcoM_FV3: A new member of "rV5-like viruses". Arch. Virol. 2012, 157, 2431-2435. [CrossRef] [PubMed]

84. Yuan, Y.; Gao, M. Jumbo Bacteriophages: An Overview. Front. Microbiol. 2017, 8, 403. [CrossRef] [PubMed]

85. Donelli, G.; Dore, E.; Frontali, C.; Grandolfo, M.E. Structure and physico-chemical properties of bacteriophage G. III. A homogeneous DNA of molecular weight 5 times 10(8). J. Mol. Biol. 1975, 94, 555-565. [CrossRef]

86. Simoliunas, E.; Kaliniene, L.; Truncaite, L.; Zajanckauskaite, A.; Staniulis, J.; Kaupinis, A.; Ger, M.; Valius, M.; Meskys, R. Klebsiella phage vB_KleM-RaK2-A giant singleton virus of the family Myoviridae. PLoS ONE 2013, 8, e60717. [CrossRef]

87. Abbasifar, R.; Griffiths, M.W.; Sabour, P.M.; Ackermann, H.W.; Vandersteegen, K.; Lavigne, R.; Noben, J.P.; Alanis Villa, A.; Abbasifar, A.; Nash, J.H.; et al. Supersize me: Cronobacter sakazakii phage GAP32. Virology 2014, 460-461, 138-146. [CrossRef] [PubMed]

88. Mesyanzhinov, V.V.; Robben, J.; Grymonprez, B.; Kostyuchenko, V.A.; Bourkaltseva, M.V.; Sykilinda, N.N.; Krylov, V.N.; Volckaert, G. The genome of bacteriophage phiKZ of Pseudomonas aeruginosa. J. Mol. Biol. 2002, 317, 1-19. [CrossRef] [PubMed]

89. Sazinas, P.; Smith, C.; Suhaimi, A.; Hobman, J.L.; Dodd, C.E.; Millard, A.D. Draft Genome Sequence of the Bacteriophage vB_Eco_slurp01. Genome Announc. 2016, 4. [CrossRef] [PubMed]

90. Kim, M.S.; Hong, S.S.; Park, K.; Myung, H. Genomic analysis of bacteriophage PBECO4 infecting Escherichia coli O157:H7. Arch. Virol. 2013, 158, 2399-2403. [CrossRef]

91. Xing, S.; Ma, T.; Zhang, X.; Huang, Y.; Mi, Z.; Sun, Q.; An, X.; Fan, H.; Wu, S.; Wei, L.; et al. First complete genome sequence of a virulent bacteriophage infecting the opportunistic pathogen Serratia rubidaea. Arch. Virol. 2017, 162, 2021-2028. [CrossRef]

92. Hsu, C.R.; Lin, T.L.; Pan, Y.J.; Hsieh, P.F.; Wang, J.T. Isolation of a bacteriophage specific for a new capsular type of Klebsiella pneumoniae and characterization of its polysaccharide depolymerase. PLOS ONE 2013, 8, e70092. [CrossRef] [PubMed]

93. Taha, O.A.; Connerton, P.L.; Connerton, I.F.; El-Shibiny, A. Bacteriophage ZCKP1: A Potential Treatment for Klebsiella pneumoniae Isolated From Diabetic Foot Patients. Front. Microbiol. 2018, 9, 2127. [CrossRef] [PubMed]

94. Tsonos, J.; Adriaenssens, E.M.; Klumpp, J.; Hernalsteens, J.P.; Lavigne, R.; De Greve, H. Complete genome sequence of the novel Escherichia coli phage phAPEC8. J. Virol. 2012, 86, 13117-13118. [CrossRef]

95. Ackermann, H.W.; Prangishvili, D. Prokaryote viruses studied by electron microscopy. Arch. Virol. 2012, 157, 1843-1849. [CrossRef] [PubMed]

96. Ackermann, H.W. Bacteriophage electron microscopy. Adv. Virus Res. 2012, 82, 1-32.

97. Rohwer, F.; Edwards, R. The Phage Proteomic Tree: A genome-based taxonomy for phage. J. Bacteriol. 2002, 184, 4529-4535. [CrossRef] [PubMed]

98. Asare, P.T.; Jeong, T.Y.; Ryu, S.; Klumpp, J.; Loessner, M.J.; Merrill, B.D.; Kim, K.P. Putative type 1 thymidylate synthase and dihydrofolate reductase as signature genes of a novel Bastille-like group of phages in the subfamily Spounavirinae. BMC Genom. 2015, 16, 582. [CrossRef]

99. Pride, D.T.; Wassenaar, T.M.; Ghose, C.; Blaser, M.J. Evidence of host-virus co-evolution in tetranucleotide usage patterns of bacteriophages and eukaryotic viruses. BMC Genom. 2006, 7, 8. [CrossRef]

(C) 2019 by the authors. Licensee MDPI, Basel, Switzerland. This article is an open access article distributed under the terms and conditions of the Creative Commons Attribution (CC BY) license (http://creativecommons.org/licenses/by/4.0/). 